\title{
BMJ Open Studying trajectories of multimorbidity: a systematic scoping review of longitudinal approaches and evidence
}

\author{
Genevieve Cezard (D) , ${ }^{1}$ Calum Thomas McHale (D) , ${ }^{2}$ Frank Sullivan, ${ }^{2}$ \\ Juliana Kuster Filipe Bowles, ${ }^{3}$ Katherine Keenan (D) ${ }^{1}$
}

To cite: Cezard G, McHale CT, Sullivan $\mathrm{F}$, et al. Studying trajectories of multimorbidity: a systematic scoping review of longitudinal approaches and evidence. BMJ Open 2021;11:e048485. doi:10.1136/ bmjopen-2020-048485

- Prepublication history and additional supplemental material for this paper are available online. To view these files, please visit the journal online (http://dx.doi.org/10.1136/ bmjopen-2020-048485).

Received 29 December 2020 Accepted 20 October 202

Check for updates

(C) Author(s) (or their employer(s)) 2021. Re-use permitted under CC BY. Published by BMJ.

${ }^{1}$ School of Geography and Sustainable Development, University of St Andrews, St Andrews, UK

${ }^{2}$ School of Medicine, University of St Andrews, St Andrews, UK ${ }^{3}$ School of Computer Science, University of St Andrews, St Andrews, UK

Correspondence to

Dr Katherine Keenan;

katherine.keenan@st-andrews. ac.uk

\section{ABSTRACT}

Objectives Multimorbidity-the co-occurrence of at least two chronic diseases in an individual-is an important public health challenge in ageing societies. The vast majority of multimorbidity research takes a cross-sectional approach, but longitudinal approaches to understanding multimorbidity are an emerging research area, being encouraged by multiple funders. To support development in this research area, the aim of this study is to scope the methodological approaches and substantive findings of studies that have investigated longitudinal multimorbidity trajectories.

Design We conducted a systematic search for relevant studies in four online databases (Medline, Scopus, Web of Science and Embase) in May 2020 using predefined search terms and inclusion and exclusion criteria. The search was complemented by searching reference lists of relevant papers. From the selected studies, we systematically extracted data on study methodology and findings and summarised them in a narrative synthesis.

Results We identified 35 studies investigating multimorbidity longitudinally, all published in the last decade, and predominantly in high-income countries from the Global North. Longitudinal approaches employed included constructing change variables, multilevel regression analysis (eg, growth curve modelling), longitudinal group-based methodologies (eg, latent class modelling), analysing disease transitions and visualisation techniques. Commonly identified risk factors for multimorbidity onset and progression were older age, higher socioeconomic and area-level deprivation, overweight and poorer health behaviours.

Conclusion The nascent research area employs a diverse range of longitudinal approaches that characterise accumulation and disease combinations and to a lesser extent disease sequencing and progression. Gaps include understanding the long-term, life course determinants of different multimorbidity trajectories, and doing so across diverse populations, including those from lowincome and middle-income countries. This can provide a detailed picture of morbidity development, with important implications from a clinical and intervention perspective.

\section{INTRODUCTION}

The term multimorbidity is used to define the co-occurrence of multiple diseases, specifically two or more chronic conditions

\section{Strengths and limitations of this study}

- This is the first systematic review to focus on studies that take a longitudinal, rather than cross-sectional, approach to multimorbidity.

- Systematic searches of online academic databases were performed using predefined search terms, as well as searching of reference lists, and this is reported using Preferred Reporting Items for Systematic Reviews and Meta-Analyses for scoping reviews guidelines.

- For selected papers, data were double extracted using standardised pro formas to aid narrative synthesis.

- Due to the heterogeneity of the studies included, their weaknesses were described in the narrative synthesis, but we did not perform quality assessment using standardised tools.

within the same individual. ${ }^{12}$ Multimorbidity represents a huge immediate and future challenge for healthcare systems around the world. It is estimated that 50 million people suffer from multimorbidity in the European Union, and about one in three globally have multiple conditions. ${ }^{34}$ The global prevalence of multimorbidity is expected to increase through the 21st century, as a result of increased life expectancy, population ageing and the expansion of morbidity. For example, the prevalence of 'complex multimorbidity'defined as four or more co-occurring chronic conditions-has been projected to increase from about $10 \%$ in 2015 to $17 \%$ in 2035 in England. ${ }^{5}$ The implications of this for individuals and societies are stark: multimorbidity is predictive of poorer quality of life, ${ }^{6}$ greater functional decline ${ }^{7}$ and increased mortality. ${ }^{8}$ Management and treatment of multimorbidity also places a considerable economic and logistical burden on health services, ${ }^{9}$ which are not adapted to deal with multimorbidity, being typically organised around the single disease model. 
In response to this challenge, in the last two decades, there has been an explosion of (predominantly crosssectional) research that has investigated the risk factors and patterns of multimorbidity. For example, systematic reviews have identified common clusters of diseases, ${ }^{10-12}$ which include cardiovascular and metabolic diseases, mental health conditions and musculoskeletal disorders. Common risk factors for multimorbidity include increasing age and low socioeconomic status (SES) ${ }^{12} 13$ and poor health behaviours, such as high body mass index and smoking. ${ }^{14}$ However, the vast majority of multimorbidity studies apply a cross-sectional approach; longitudinal approaches are scarce. To date, there are more than 70 published systematic reviews about multimorbidity, covering definitions to interventions (eg, refs 2 $15)$, and none of these focuses on longitudinal studies. While 'snap-shot' analyses are useful for understanding prevalence and clustering of diseases, they provide little information on multimorbidity development over time and sequencing of diseases, which have important implications from a clinical and intervention perspective. Recently, there has been a growing orientation towards longitudinal approaches by academic communities and funders such as the UK's Academy of Medical Sciences. ${ }^{4}$

Therefore, this paper aims to gain an overview of the longitudinal approaches used in multimorbidity research, to better understand what evidence is generated from these approaches and to identify the associated gaps.

Our research questions are:

1. What type and range of longitudinal methods are used to analyse multimorbidity over time within individuals?

2. What are the risk/protective factors identified to be associated with individual multimorbidity trajectories?

We used a scoping review approach to systematically review the emerging body of literature investigating multimorbidity trajectories. Based on a narrative synthesis focused on commonalities and differences, this review provides a methodological summary and a comprehensivereview of the evidence on factors affecting multimorbidity pathways.

\section{METHODS}

We review the literature on longitudinal multimorbidity studies via a scoping review approach rather than using a systematic review or meta-analytic approach. ${ }^{16}$ Scoping reviews are adopted when the purpose of the review is to scope a nascent body of literature and appraise gaps. ${ }^{17} 18$ In reporting, we follow the recently developed Preferred Reporting Items for Systematic Reviews and MetaAnalyses for scoping reviews (PRISMA-ScR) ${ }^{19}$ (online supplemental appendix A).

\section{Eligibility criteria}

Inclusion and exclusion criterion were defined prior to database searches (table 1). A primary eligibility criterion was to measure multimorbidity longitudinally within the same sample of adults using a quantitative approach, and we excluded cross-sectional or qualitative designs, reviews, meta-analyses and commentary that did not contain empirical results. Studies had to measure multimorbidity through recognised diseases/conditions or a defined multimorbidity measure such as the Charlson or Elixhauser comorbidity indices ${ }^{20}$ but not solely a collection of symptoms/states (such as disability or frailty) or disease risk factors (such as obesity). Studies were required to measure change in multimorbidity between distinguishable diseases rather than progression within a single disease category (eg, different types of cancer). We also excluded studies that examined transitions from an index disease into a secondary disease (eg, comorbidities of diabetes). Finally, included studies were focused on

Table 1 Study inclusion/exclusion criteria for the scoping review

\begin{tabular}{|c|c|}
\hline & Inclusion \\
\hline Study design & $\begin{array}{l}\text { Repeated measures designs, longitudinal } \\
\text { quantitative studies, including retrospective } \\
\text { and prospective cohort studies. }\end{array}$ \\
\hline
\end{tabular}

\section{Exclusion}

Cross-sectional studies.

Systematic reviews/meta-analyses.

Qualitative studies.

Expert opinion/committee reports.

Methodology Measure trajectories of multimorbidity longitudinally within the same individuals. Multimorbidity defined as a combination of recognised diseases/conditions (eg, self-report or International Classification of Disease 9th revision (ICD-9) or 10th revision (ICD-10) codes).

Trajectories defined as change or accumulation in number of distinguishable diseases.

$\begin{array}{lll}\text { Population } & \text { Adult humans (18+ years). } & \begin{array}{l}\text { Infants, children or adolescents }(<18 \text { years). } \\ \text { Animal research. }\end{array} \\ \text { Publication } & \text { Peer-reviewed journal articles. } & \text { Grey literature. } \\ & \text { Accessible in English. } & \text { Not accessible in English. }\end{array}$

Different cohorts/samples used across longitudinal study timeline.

Multimorbidity defined as combination of symptoms or predisease conditions, that is, not defined ICD-10 diseases (eg, predisease, frailty, disability and quality of life). Transitions or trajectories within a single disease (eg, dementia) or from one disease into another (eg, cancer progression).

Not accessible in English. 
Table 2 Summary of search strategy

\section{Search no. Search terms}

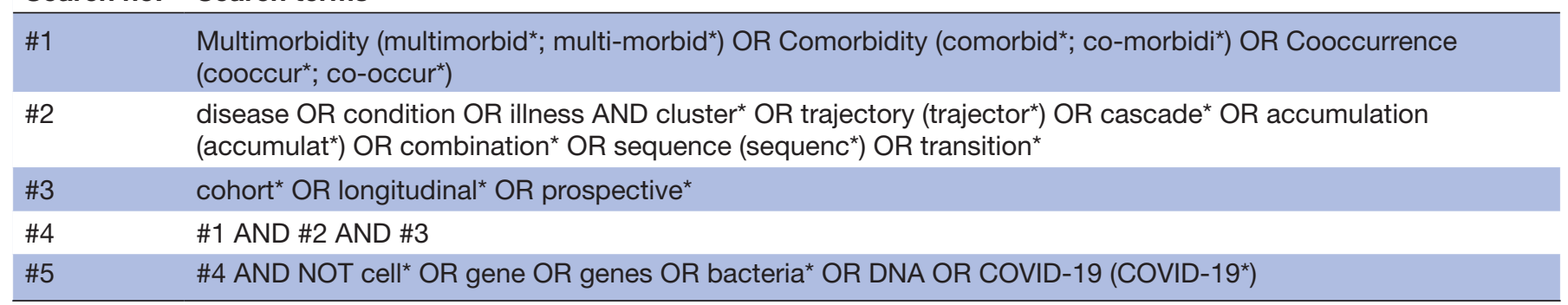

adult humans (aged 18+ years) and were peer-reviewed journal articles, written in English language. Our search had no restrictions on date of publication.

\section{Search strategy}

Four online databases were searched: Medline, Scopus, Web of Science and Embase. Initially, scoping searches were conducted within each database, with relevant terms such as 'multimorbidity', 'disease trajectory' and 'longitudinal'. These scoping searches allowed the identification of additional relevant search terms and, where appropriate, Medical Subject Headings (MeSH), in order to develop and refine the final search strategy (table 2).

The final search was a combination of three search elements: first, the concept of multimorbidity, second the methodological approach of disease trajectories and third, longitudinal study design. These search terms initially returned a large number of irrelevant references, focusing on cellular medicine, genetics and COVID-19, so we added an additional condition to exclude these. We also refined the search results to include English language, adult humans and peer-reviewed journal articles only. All searches were conducted in May 2020. The full search syntax is included in online supplemental appendix 1, appendix B. We identified additional relevant papers through recommendations from coauthors and external collaborators. The database search results were searched for these additional papers, and if they were not identified in the database searches, they were included as 'identified through other sources' and were subject to the same screening procedure as papers identified through database searches.

\section{Screening and study selection}

After deduplication, articles were screened for eligibility by title, abstract and finally full text using Endnote and predefined groups for exclusion reasons and inclusion (work shared between GC, CTM and KK). At abstract and full-text stages, a double screening process was used to minimise evidence selection bias, ${ }^{22}$ meaning two coauthors blindly and independently reviewed the study for inclusion. Any disagreements were resolved through discussion and consensus. The reference lists of the selected studies were screened to identify any relevant studies that may have been missed in the main search, and any newly identified articles were subject to the same screening and data extraction processes.

\section{Data extraction and synthesis}

Three authors (GC, CTM and KK) extracted and doubleextracted information on study and sample characteristics, including the title, authors and publication year, study setting, data source used, information on the study population (eg, inclusion and exclusion criteria, sample size and age) and follow-up duration. We also extracted study objectives, multimorbidity conceptualisation and measures, and methodological and analytical approaches, focusing on those specifically used for the analysis of multimorbidity trajectories. Finally, we extracted the key substantive findings and limitations reported in each study in relation to generalisability, accuracy, comprehensiveness, methodology and interpretation.

To develop the narrative synthesis, we analysed and summarised the patterns in the extracted data, investigated the similarities and differences between studies and examined bias and limitations to identify knowledge gaps and the strengths and weaknesses of methodological approaches.

\section{Ethics approval}

This is a review of already published material; therefore, no ethics approval needed.

Patient and public involvement

No patient involved.

\section{RESULTS}

\section{Study selection}

Figure 1 depicts the study selection process. Database searches returned 11420 articles and nine additional papers were identified from other sources. Of the combined 11429 papers, 4705 were duplicate references and removed. Of the remaining 6724 papers, 6315 were removed during title screening and a further 360 papers during abstract screening. The most common reasons for exclusion were studies that did not focus on multimorbidity longitudinally (eg, trajectories were followed within a single disease) and study design not being longitudinal (eg, cross-sectional analysis). The remaining 49 papers went through full-text screening and 19 were 


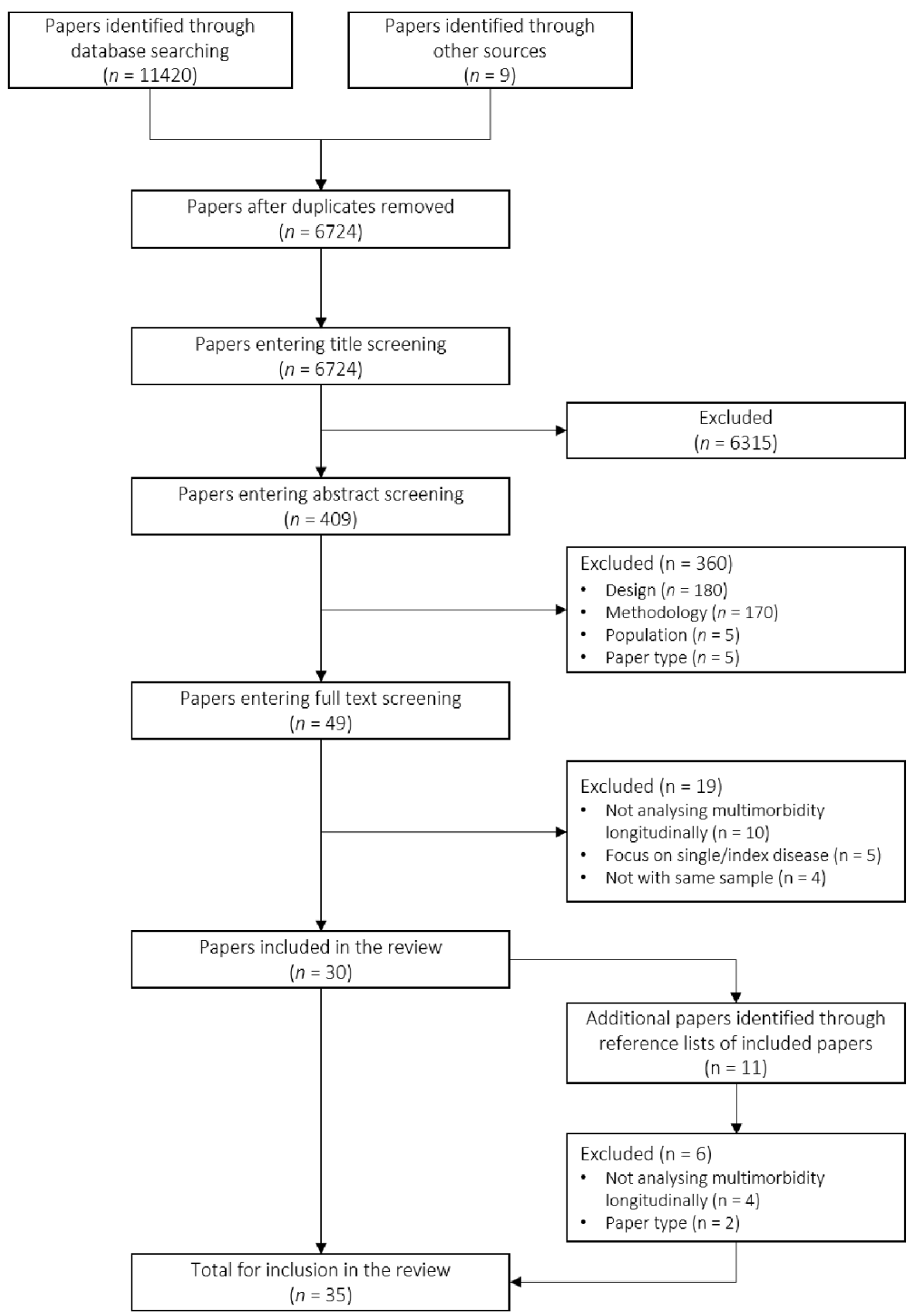

Figure 1 Study selection process.

subsequently removed. Searching the reference lists of the remaining 30 papers identified another 11 potentially relevant papers. After screening these 11 papers, six were excluded leaving five additional papers for inclusion. In total, 35 papers were selected for further data extraction.

\section{Characteristics of the selected studies}

Table 3 summarises the study characteristics. All articles were published since 2011 and were primarily based on data from European countries $(\mathrm{n}=16),{ }^{23-38}$ Australia and North America $(\mathrm{n}=14)^{39-52}$ and high-income Asian countries South Korea, Taiwan and Singapore $(n=4))^{53-56}$ Apart from one study using Chinese data, ${ }^{57}$ none related to low-income and middle-income settings.
Sample characteristics varied widely, ranging from 756 in a survey of older participants ${ }^{45}$ to 6.2 million in a nationwide study using Danish register data ${ }^{38}$ and the length of follow-up periods ranged between 2 and 20 years. Most studies had age restrictions, with about half focused on older populations (50 years + ), and one study focused on the very old (80 years plus) ${ }^{36}$ Most samples included both males and females apart from two studies including males only $^{2637}$ and three studies including females only. 4751 Three studies focused on US veterans, a predominantly male population. ${ }^{3944} 48$ The data sources used were a combination of administrative data, including primary or secondary care records, disease registries and health insurance data (24 studies), and survey data (18 studies). 


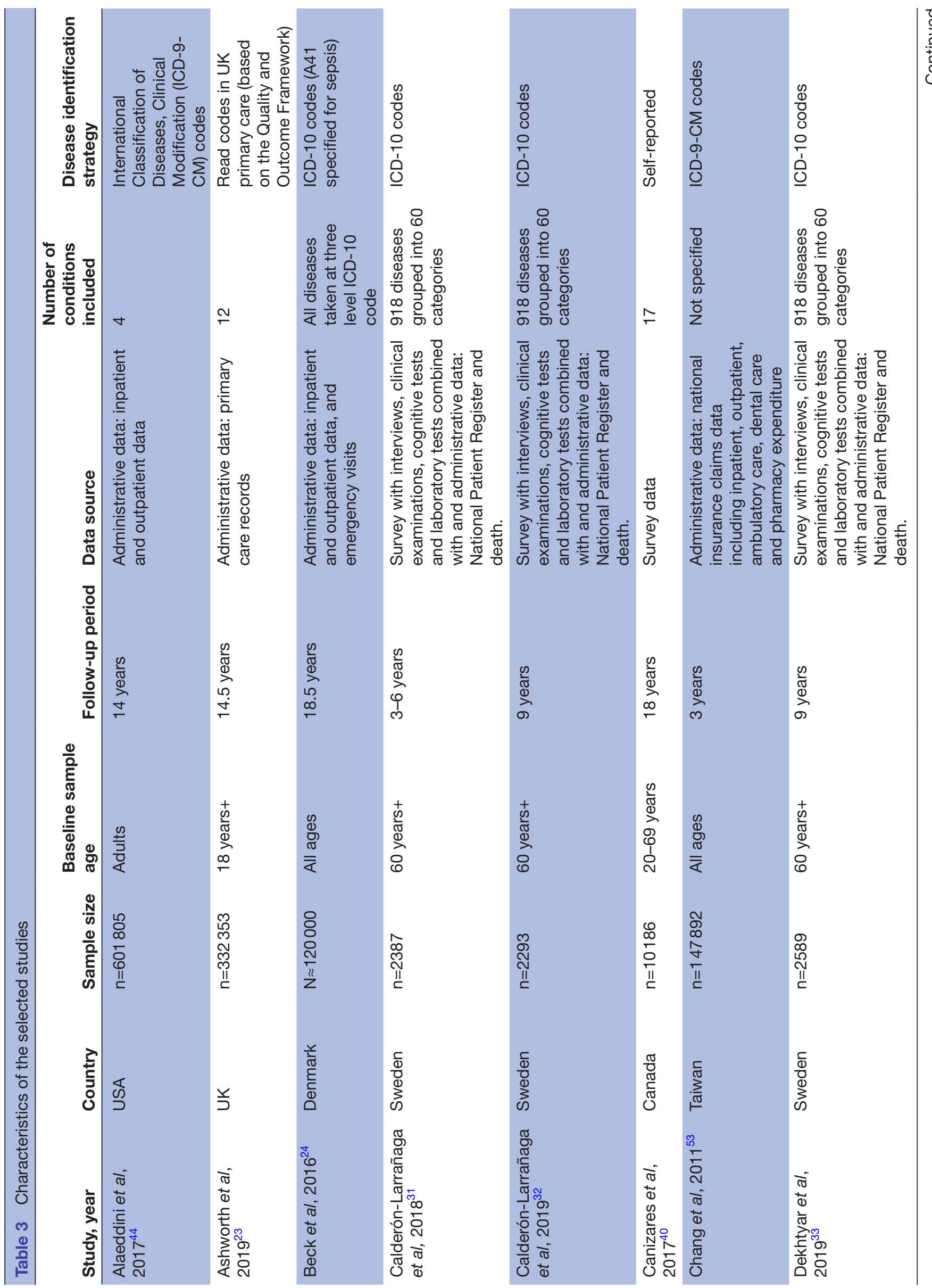




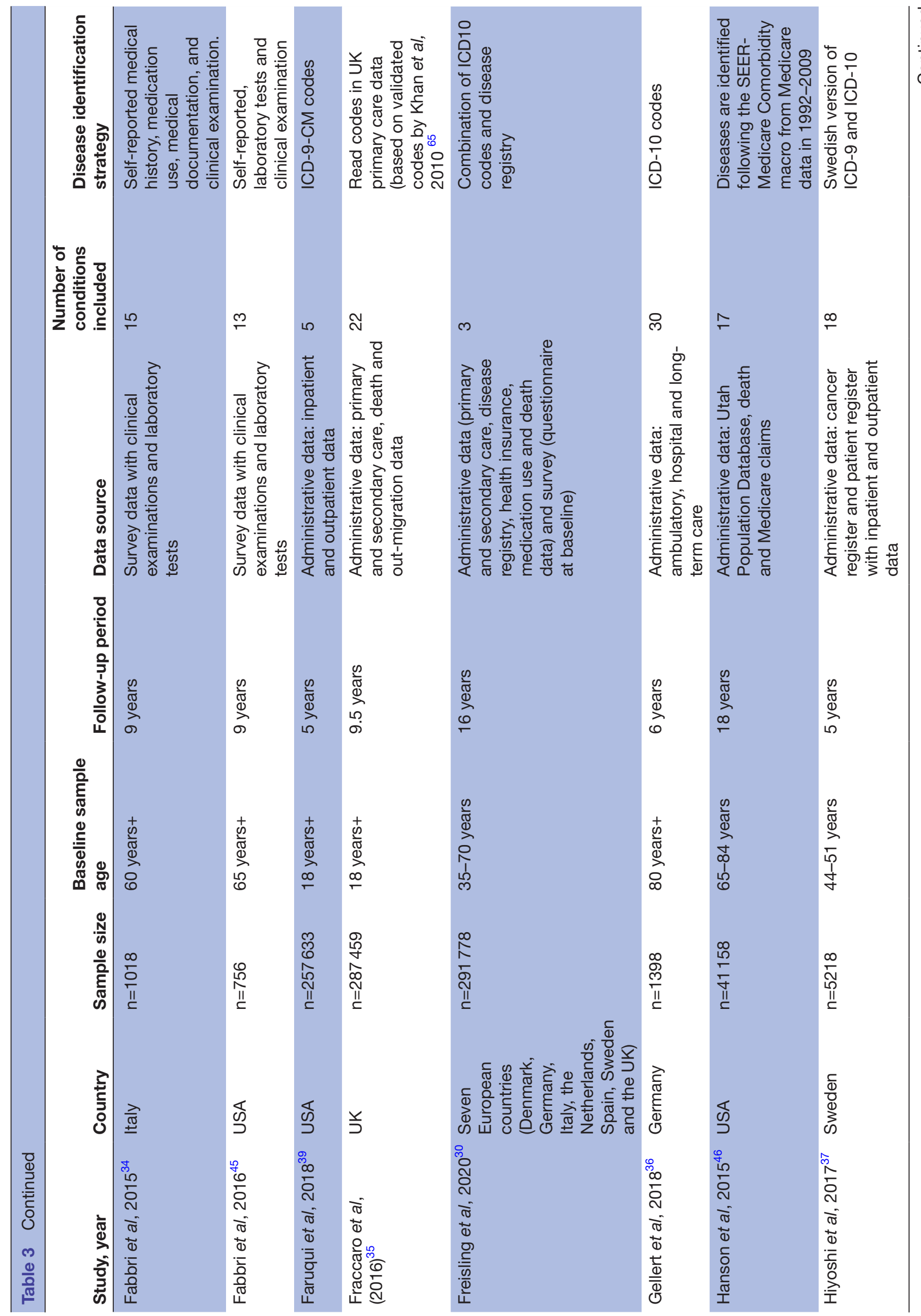

용

$\stackrel{8}{?}$

言

$\frac{\overline{0}}{\frac{\bar{\sigma}}{\sigma}}$ 


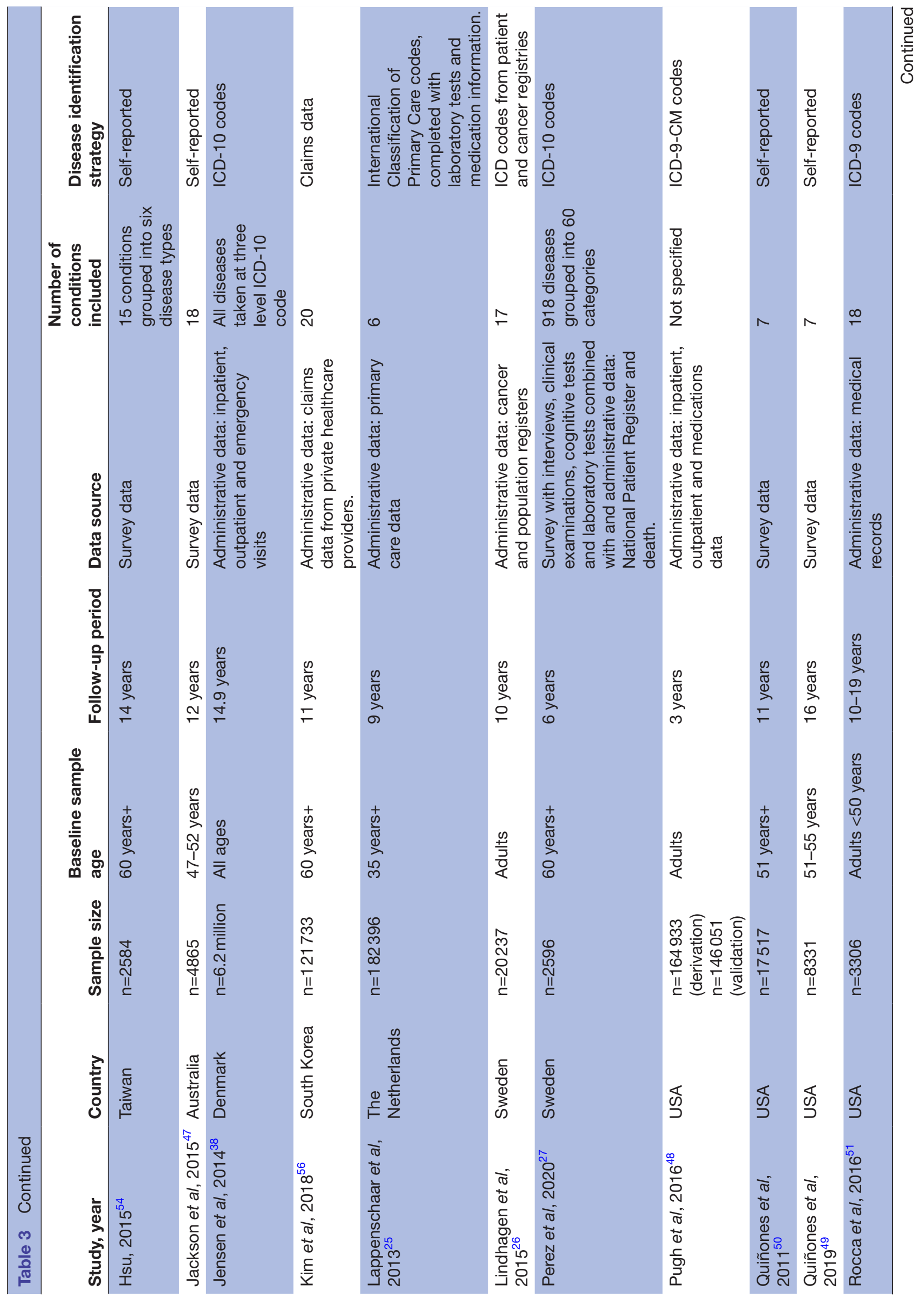




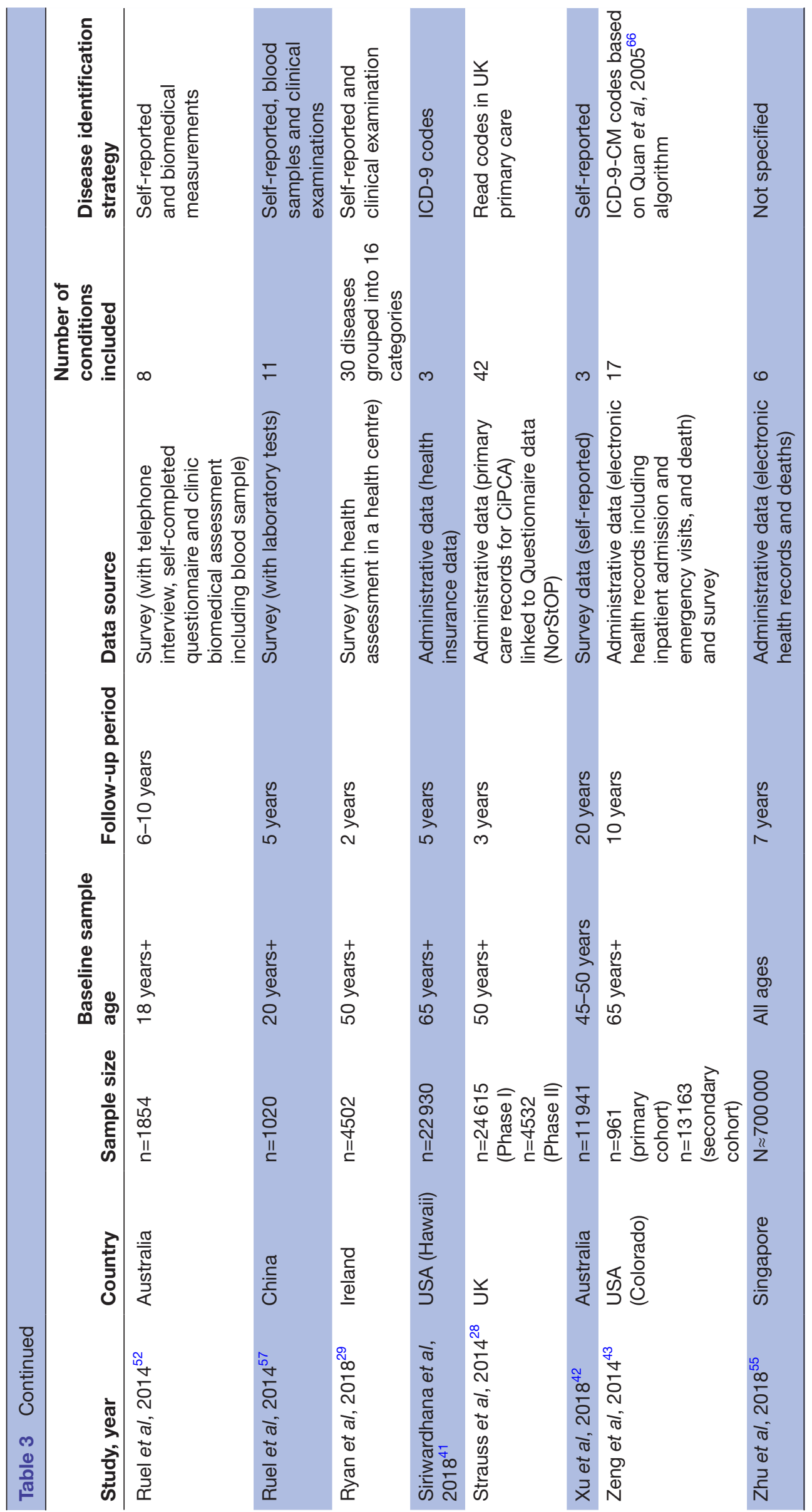


There were common datasets used across studies, such as the Swedish National study on Ageing and Care in Kungsholmen. ${ }^{27}{ }^{31-33}$ In seven studies, survey data were combined with administrative data sources. ${ }^{27} 28$ 30-33 43 In five survey-based studies, questionnaire data were supplemented by medical examination records or cognitive or laboratory tests. ${ }^{29} 34455257$ Informed consent of participants was mentioned in 10 of the 18 studies using survey data.

\section{Methods of disease and multimorbidity ascertainment}

Studies based on administrative data relied on cliniciandiagnosed diseases, often using standardised diagnosis codes, such as the International Classification of Diseases, that is, International Classification of Disease 9th revision (ICD-9), ICD-9, Clinical Modification (ICD-9-CM), or ICD 10th revision (ICD-10). All survey-based studies used participant self-report for disease identification. Studies that combined survey data with other sources ascertained disease status mostly through clinician diagnosis ${ }^{27}$ 28 30-3343 but some supplemented with laboratory and cognitive tests. ${ }^{29} 34455257$ The number of diseases that were considered to contribute to the measure of multimorbidity varied widely, ranging from three ${ }^{304142}$ to a very large number based on three levels of ICD-10 codes. ${ }^{24}{ }^{38}$ Studies using survey data used a narrower range of diseases than those drawn from administrative data. The precise list of diseases was never uniform between studies (see appendix C for full details), but the rationale for choosing them was usually described. For example, included diseases with high prevalence and risk of disability and mortality ${ }^{34} 45$ or that were assessed/validated by clinicians. ${ }^{27} 28$ 31-33 Some used lists based on the Charlson and Elixhauser multimorbidity indices, ${ }^{26} 35-37434656$ but these were sometimes augmented with extra conditions ${ }^{37}$ or reduced due to data sensitivity restrictions. ${ }^{35}$

\section{Approaches to the measurement of multimorbidity trajectories}

To develop longitudinal measures of multimorbidity, studies tended to take one of two broad approaches. The most common was that repeated measures of multimorbidity status over time were measured for each individual. This mainly involved constructing unweighted or weighted counts of diseases at regular intervals for each individual, thus conceptualising multimorbidity as a continuum (eg, refs 52 57), although a few still used a binary measure of two or more chronic conditions. ${ }^{29} 40$ The second broad approach explored disease transitions. ${ }^{24-2630383941424455}$ Only one study explored the order of disease occurrence. ${ }^{23}$

\section{Types of methodology}

Breaking this down further, we identified five broad analytical approaches: constructed variables of multimorbidity change, multilevel regression modelling, transition and data mining methodologies, visual approaches (articles summarised in table 4) and longitudinal group-based methodologies (articles summarised in table 5). Note that some studies employed more than one type of approach (eg, refs 42). In the first approach, four articles created variables of multimorbidity change. ${ }^{29} 355357$ In one study, intraindividual change in Charlson Comorbidity Index (CCI) between baseline and later time points was used, ${ }^{35}$ and in another, transitions to two or more conditions or by acquisition of additional conditions. ${ }^{29}$ Two studies used simple methods to construct morbidity trajectory groups (eg, 'constant high', 'constant medium' and 'constant low' $)^{53}$ and disease transition stages (eg, 'healthy' and 'healthy to a single chronic disease'). ${ }^{57}$ After creating these categorical dependent variables, the authors used them in regression analysis to assess their association with health expenditures ${ }^{53} \operatorname{diet}^{57}$ and physical activity and functioning. ${ }^{29}$

The next approach, employed by 14 studies (table 4), ${ }^{27} 31-3640424345495052$ was multilevel regression modelling (variously referred to as random effects models, growth curve models, hierarchical linear models or multilevel models). These studies analyse repeated measures of multimorbidity within each individual, considering this as a 'trajectory' or 'growth curve'. The dependent variable was typically a count of diseases or a multimorbidity index measured repeatedly, and the coefficients assessed a change in this over time, many including random effects for both the intercept and slope. One study used the regression estimates (ie, intercept and slope coefficients for multimorbidity) to create categories capturing the pace of multimorbidity, for example, 'rapidly accumulating' and 'slowly accumulating', which were used for further modelling. ${ }^{31}$ Some of these studies also investigated whether certain covariates such as biomarkers, ${ }^{27} 34$ sociodemographics and life experiences ${ }^{33}$ affected the pace of change in multimorbidity by including an interaction term between time and the respective covariates.

The next approach, employed by nine studies, ${ }^{24-26} 303839414455$ focused on modelling transitions between specific disease states. Six of the studies focused on a limited number of diseases to make the analysis feasible. ${ }^{25} 3039414455$ Some studies used principles of state transition modelling, either using Markov principles, ${ }^{44}$ acyclic multistate models ${ }^{41}$ or state transition modelling. ${ }^{26}{ }^{30}$ Another two studies employed Bayesian techniques including a multilevel temporal Bayesian network $^{25}$ and a longest path algorithm to identify the most probable sequence from/to a specific disease following an unsupervised multilevel temporal Bayesian network analysis. ${ }^{39}$ One paper derived a disease progression network from real data and used this for further microsimulation ${ }^{55}$ Finally, two studies used a data-driven approach to create 'temporal disease trajectories' by combining significant temporal directed pairs from all disease pairs possible. ${ }^{24} 38$ Transition analysis also enabled the identification of longitudinal clusters. ${ }^{44}$

Three studies ${ }^{234251}$ used visual methods to describe disease sequences or multimorbidity acquisition sequences. Ashworth et $a l^{23}$ used alluvial plots to illustrate multimorbidity acquisition sequences based on date 
Table 4 Methods of studies taking four analytical approaches (multimorbidity change variables, regression, transition modelling and visual approaches)

\section{Approach 1: constructed variables of multimorbidity change $(n=4)$}

Study, year Main study outcome Statistical methodology used to analyse multimorbidity longitudinally

Chang et al, $2011^{53} \quad$ Prospective medical use Morbidity trajectory groups: constant high, constant medium, constant low, decreasing, and expenditures increasing and erratic.

Fraccaro et al, $2016^{35}$ Time to death from any Change in comorbidities: difference between baseline Charlson Comorbidity Index (CCI) cause and 1-year, 5-year and 10-year follow-up $\mathrm{CCl}$ scores as a proportion of mortality rate.

Ruel et al, $2014^{57} \quad$ Six chronic disease transition stages groups Groups of chronic disease transition stages (healthy, healthy to a single chronic disease, stable with a single chronic disease, healthy to multimorbidity, stable multimorbidity and increasing multimorbidity)

Ryan et al, $2018^{29} \quad$ Development/worsening Constructed measures of multimorbidity change (from zero or one condition at baseline of multimorbidity to two or more conditions) and of worsening of multimorbidity (from multimorbidity at baseline to additional conditions at follow-up)

\section{Approach 2: regression-based approaches $(n=14)$}

Calderón-Larrañaga et Disability (IADL ${ }^{*}$ count) al, $2018^{31}$

$\begin{array}{ll}\begin{array}{l}\text { Caldeón-Larrañaga et } \\ \text { al, 201932 }\end{array} & \begin{array}{l}\text { Level of multimorbidity } \\ \text { (count of chronic } \\ \text { conditions) and disability } \\ \text { (IADL count) }\end{array} \\ \text { Canizares et al, 2017 } & \begin{array}{l}\text { Multimorbidity (binary - } \\ \text { two or more conditions) }\end{array} \\ \text { Dekhtyar et al, 2019 } & \begin{array}{l}\text { Level of multimorbidity } \\ \text { (count of chronic } \\ \text { conditions) }\end{array} \\ \text { Fabbri et al, 2015 } & \begin{array}{l}\text { Level of multimorbidity } \\ \text { (count of chronic } \\ \text { conditions) }\end{array}\end{array}$

Fabbri et al, $2016^{45} \quad$ Standardised neurocognitive tests evaluating cognitive function

Fraccaro et al, $2016^{35}$ All-cause mortality

$\begin{array}{ll}\text { Gellert et al, 2018 } & \text { Level of multimorbidity } \\ & \begin{array}{l}\text { (count of comorbidities- } \\ \text { based on Elixhauser) }\end{array} \\ \text { Perez et al, 202027 } & \begin{array}{l}\text { Level of multimorbidity } \\ \text { (count of chronic } \\ \text { conditions) }\end{array}\end{array}$

$\begin{array}{ll}\text { Quñones et al, 2011 } & \text { Level of multimorbidity } \\ & \begin{array}{l}\text { (count of chronic } \\ \text { conditions) }\end{array} \\ \text { Quñones et al, 201949 } & \begin{array}{l}\text { Level of multimorbidity } \\ \text { (count of chronic } \\ \text { conditions) }\end{array}\end{array}$

Ruel et al, $2014^{52} \quad$ Count of chronic conditions+incidence of multimorbidity

Xu et al, $2018^{42}$
Linear mixed models $†$ estimated the rate of multimorbidity accumulation. Predicted slopes are examined by quartile and further dichotomised into 'rapidly accumulating' (upper quartile) and 'slowly accumulating' (three lower quartile).

Linear mixed models assessed the association between baseline level of psychological factors and multimorbidity and disability over time. The interaction terms between time and each of the psychological factors were included as a fixed effect.

Multilevel logistic growth modelling was used to examine the age, period and cohort effects on multimorbidity. Observations nested in individuals and age and birth cohort entered as fixed effects.

Linear mixed models assessed the association between life experiences and the speed of multimorbidity accumulation. Interaction terms between time and life experiences included as fixed effects.

Linear mixed models assessed the association between baseline age, disease status and biomarkers with the number of diseases over follow-up. The study also tested whether increased Interleukin 6 (IL-6) over time would predict steeper increase in multimorbidity over time, independent of baseline IL-6.

Linear mixed models were used to estimate rate of change in multimorbidity (count of diseases). The individual slopes of multimorbidity rise were dichotomised into faster accumulation (upper quartile) and the rest (lower three quartiles).

Multimorbidity change was measured by differences between baseline $\mathrm{CCl}$ and 1-year, 5year and 10-year follow-up CCl scores as a proportion of mortality rate. Survival analysis (Cox regression) estimated mortality rates as a function of age, gender and $\mathrm{CCl}$ scores (fixed and time varying).

Linear mixed models (random intercepts and slopes) estimated differential increase in the number of comorbidities over 25 calendar quarters prior to death in centenarian, nonagenarian and octogenarian cohorts.

Linear mixed models (random intercepts and slopes) were employed to analyse the association between baseline total serum glutathione levels and level of multimorbidity.

Linear mixed models (random intercepts and slopes) analysed ethnic variations in level of multimorbidity.

Negative binomial generalised estimating equation (GEE) models with a first-order autoregressive covariance structure were used to assess the relationship between chronic disease accumulation and race/ethnicity.

Multinomial logistic regression estimated the count and individual proportion of chronic diseases in those with no or one chronic disease at baseline.

Cumulative incidence of Repeated measures logistic regression using GEEs were used to identify risk factors for three conditions (diabetes, developing three conditions and their combinations. Generalised linear mixed models heart disease and stroke) were used to estimate the associations between predictors and the progression to multimorbidity. 
Table 4 Continued

\begin{tabular}{lll}
\hline Approach 1: constructed variables of multimorbidity change $(\mathbf{n}=4)$ \\
\hline Study, year & Main study outcome & Statistical methodology used to analyse multimorbidity longitudinally \\
\hline Zeng et al, 2014 & $\begin{array}{l}\text { Self-reported health, } \\
\text { number of primary }\end{array}$ & $\begin{array}{l}\text { Linear mixed models (random intercepts and slopes) estimated the individual trajectory } \\
\text { of CCl over time (up to 10 years), which was used as an independent variable in a }\end{array}$ \\
& $\begin{array}{l}\text { care visits, inpatient } \\
\text { admissions, emergency } \\
\text { department visits and } \\
\text { mortality }\end{array}$
\end{tabular}

\section{Approach 3: transition and disease progression modelling $(n=9)$}

\begin{tabular}{|c|c|c|}
\hline Alaeddini et al, $2017^{44}$ & $\begin{array}{l}\text { Clusters of disease } \\
\text { transition considering four } \\
\text { conditions (hypertension, } \\
\text { depression, post- } \\
\text { traumatic stress disorder } \\
\text { and back pain) }\end{array}$ & $\begin{array}{l}\text { Disease transitions were modelled using Markov chain models with a transition matrix, } \\
\text { placed in a Latent Regression Markov Mixture Model to incorporate subject-specific } \\
\text { covariates (eg, age, sex, race/ethnicity, etc). Markov Clustering algorithm was used to } \\
\text { identify patterns of disease progression. }\end{array}$ \\
\hline Beck et al, $2016^{24}$ & $\begin{array}{l}\text { 30-day mortality in } \\
\text { patients with sepsis }\end{array}$ & $\begin{array}{l}\text { Data-driven method combining temporal directed pairs for identification of disease } \\
\text { trajectories based on the method developed by Jensen et } a^{38}\end{array}$ \\
\hline Freisling et al, $2020^{30}$ & $\begin{array}{l}\text { Transition to cancer- } \\
\text { cardiometabolic } \\
\text { multimorbidity }\end{array}$ & $\begin{array}{l}\text { Non-Markovian multistate modelling for transitions to cancer, cardiovascular disease } \\
\text { (CVD), type } 2 \text { diabetes and subsequently to multimorbidty using cox proportional } \\
\text { hazards. }\end{array}$ \\
\hline Faruqui et al, $2018^{39}$ & $\begin{array}{l}\text { Development of five } \\
\text { specific conditions }\end{array}$ & $\begin{array}{l}\text { Comparison of several methods: unsupervised Bayesian network, multivariate regression } \\
\text { and latent regression Markov mixture modelling. Longest Path Algorithm from the } \\
\text { Bayesian network was used to identify the most probable sequence from/to a specific } \\
\text { disease. }\end{array}$ \\
\hline Jensen et al, $2011^{38}$ & Disease trajectories & $\begin{array}{l}\text { Temporal correlation analysis, that is, strength of correlation between the pair of diseases } \\
\text { (relative risk }>1 \text { ) for over a million pairs where disease } 2 \text { (D2) occurs within } 5 \text { years of } \\
\text { disease } 1 \text { (D1) and based on directionality (whether D1->D2 occurs more often than D2- } \\
\text { >D1, binomial tests). Disease trajectories combining pairs with overlapping diagnosis, } \\
\text { into three or more diseases. }\end{array}$ \\
\hline Lindhagen et al, $2015^{26}$ & $\begin{array}{l}\text { Mortality; change and } \\
\text { scale of } \mathrm{CCl} \text { change }\end{array}$ & $\begin{array}{l}\text { A state transition model in discrete time steps to estimate changes in } \mathrm{CCl} \text {. Transition } \\
\text { probabilities were estimated using logistic/Poisson regression models for vital status and } \\
\mathrm{CCl} \text { changes. Simulation models estimated changes in } \mathrm{CCl} \text { with their Cls. }\end{array}$ \\
\hline $\begin{array}{l}\text { Lappenschaar et al, } \\
2013^{25}\end{array}$ & $\begin{array}{l}\text { Cumulative incidence } \\
\text { and combinations of six } \\
\text { cardiovascular diseases }\end{array}$ & $\begin{array}{l}\text { Multilevel temporal Bayesian networks were used to model the patient's disease status } \\
\text { at baseline and 3-5 years after. The variance induced by the urbanisation level, age } \\
\text { and gender in the multilevel model was explained using Markov Chain Monte Carlo } \\
\text { simulation. }\end{array}$ \\
\hline $\begin{array}{l}\text { Siriwardhana et al, } \\
2018^{41}\end{array}$ & $\begin{array}{l}\text { Disease state probability } \\
\text { and transition probability } \\
\text { from a single disease } \\
\text { state to a multiple disease } \\
\text { state. }\end{array}$ & $\begin{array}{l}\text { Acyclic multistate model to define an interconnected progressive chronic disease system } \\
\text { for the elderly population. } \\
\text { Aalen and Johansen estimator (a non-parametric technique) to estimate marginal state } \\
\text { occupational probabilities. }\end{array}$ \\
\hline Zhu et al, $2018^{55}$ & $\begin{array}{l}\text { Disease progression } \\
\text { states and the absorbing } \\
\text { state, death. Life years } \\
\text { lost to a specific condition } \\
\text { and cumulative lifetime } \\
\text { risk of certain conditions }\end{array}$ & $\begin{array}{l}\text { A disease progression network was constructed based on the real cohort. One-year } \\
\text { progression from state } A \text { to } B \text { is calculated by counting the number of people who are } \\
\text { in state } A \text { the previous year and in state B the following year. Microsimulation is used to } \\
\text { calculate life years lost and lifetime risk of particular states. }\end{array}$ \\
\hline
\end{tabular}

Approach 4: visualisation methods $(n=3)$

\begin{tabular}{lll} 
Ashworth et al, 2019 & $\begin{array}{l}\text { Level of multimorbidity } \\
\text { (count of chronic } \\
\text { conditions) }\end{array}$ & $\begin{array}{l}\text { Alluvial plots based on date of onset of each long-term condition, tabulated as first, } \\
\text { second and third to visualise the acquisition sequence. }\end{array}$ \\
Rocca et al, 2016 & $\begin{array}{l}\text { Level of multimorbidity } \\
\text { (count of chronic } \\
\text { conditions) }\end{array}$ & $\begin{array}{l}\text { The accumulation of multimorbidity was represented graphically using Aalen-Johansen } \\
\text { curves (a multistate generalisation of cumulative incidence curves; unadjusted curves } \\
\text { considering all 18 conditions equally). }\end{array}$ \\
\hline Xu et al, 2018 & $\begin{array}{l}\text { Cumulative incidence of } \\
\text { three conditions }\end{array}$ & $\begin{array}{l}\text { Sankey diagram was constructed to characterise the dynamic changes of different } \\
\text { combinations of the three conditions over time. }\end{array}$
\end{tabular}

* $I A D L=$ limitations in instrumental activities of daily living.

†Linear mixed models here refer to any multilevel model for repeated measures over time for each individual, incorporating various labels - mixed linear model, hierarchical models, growth curve model, etc. 
Table 5 Methods of studies investigating multimorbidity trajectory groups

\begin{tabular}{ll}
\hline Study, year & Statistical approach used \\
\hline Hanson et al, & Finite mixture modelling (Proc TRAJ in SAS) \\
$2015^{46}$ & was used, with a zero-inflated distribution. \\
& Optimal number of groups determined by \\
& Bayesian Information Criterion (BIC).
\end{tabular}

Trajectory groups identified

Six groups: 'robust' (no conditions), 'initiates' (none at baseline, increase over time), 'slow initiates' (some at baseline and gradual increase over time), 'accelerated initiates' (none at baseline and quick increase followed by deceleration), 'chronic low' (steady comorbidity over time), 'ailing' (moderate levels of comorbidity at baseline and steady increase over time), 'frail' (high comorbidity at baseline, remaining high over time).

Hiyoshi et al, Group-based trajectory modelling, using a Four groups identified: 'a constant low trajectory', 'a low start $2017^{37} \quad$ zero-inflated distribution. Optimal number of groups determined using BIC.

$\begin{array}{ll}\text { Hsu, 2015 } & \text { Multiple group-based trajectory model } \\ & \text { (Proc TRAJ in SAS). Morbidity was set to } \\ & \begin{array}{l}\text { follow a logistic model. The optimal group } \\ \text { number was determined using the BIC and } \\ \text { parsimony principle. }\end{array} \\ \text { Jackson et al, } & \begin{array}{l}\text { Latent class growth analysis (LCGA) in } \\ 2015^{47}\end{array} \\ & \begin{array}{l}\text { Mplus; optimal group number determined } \\ \text { using BIC. }\end{array}\end{array}$
increase trajectory' and 'a high start and a slow increase trajectory'.

Four chronic disease trajectories were identified: 'low risk', 'cardiovascular risk only', 'gastrointestinal and chronic nonspecific lung disease' and 'multiple risks'.

$\begin{aligned} \text { Kim et al, } 2018^{56} & \text { Growth mixture modelling in SAS was used; } \\ & \text { optimal group number determined using } \\ & \text { BIC. }\end{aligned}$

Pugh et al, Latent Class Analysis, based on the $2016^{48}$ distribution of repeated measures in the 20 binary diagnosis outcomes.

Five groups identified: 'no morbidity, constant', 'low morbidity, constant', 'moderate morbidity, constant', 'no morbidity, increasing' and 'low morbidity, increasing'.

Five groups identified: 'consistently low', 'increased', 'decreased (low)', 'decreased (high)' and 'consistently high'.

Five groups identified for both men and women: 'Healthy', 'Chronic Disease', 'Mental Health', 'Pain' and 'Polytrauma Clinical Triad (PCT pain, mental health and traumatic brain injury'. Two additional classes found in men were 'Minor Chronic' and 'PCT with chronic disease'.

$\begin{array}{ll}\text { Strauss et al, } & \text { LCGA in Mplus, optimal group number } \\ 2014^{28} & \text { determined by iterative modelling and BIC } \\ & \text { values and likelihood ratio test. Morbidity } \\ & \text { counts were assumed to be Poisson } \\ & \text { distributed. Quadratic growth curves were } \\ & \text { applied for all groups identified within the } \\ & \text { LCGA models. }\end{array}$

of disease onset, and although useful to understand the order of diseases (co-) occurrence, the visualisations are unable to account for the pace of multimorbidity progression. Aalen-Johansen curves (a multistate generalisation of cumulative incidence curves) were used to represent the accumulation of multimorbidity graphically ${ }^{51}$ and the Sankey diagram to show the longitudinal progression and transitions to each disease and disease combinations. ${ }^{42}$

The final approach, employed by seven studies, ${ }^{28} 3746-485456$ was to construct meaningful categories of longitudinal multimorbidity patterns (and associate these with other covariates (summarised in table 5). Methodologies included latent class analysis, latent class growth analysis, growth mixture modelling or group-based trajectory modelling and typically identified between four and six groups of distinct longitudinal multimorbidity patterns. Two studies took an associative approach to explore that specific diseases cluster longitudinally. ${ }^{48}$ For example, $\mathrm{Hsu}^{54}$ found four trajectory groups: 'low risk', 'cardiovascular risk only', 'gastrointestinal and chronic non-specific lung disease' and 'multiple risks'. The other five studies focused on stages of accumulation. Hiyoshi $e t a l^{77}$ found four trajectory groups ranging from 'a constant low trajectory' to 'a high start and a slow increase trajectory'. Generally, these clusters incorporated data on the initial level of multimorbidity, and accumulation pattern over time, and nearly all showed accumulation (the exception being Kim et $a l^{56}{ }^{56}$ which identified some groups with decreasing morbidities).

\section{Results of the studies: outcomes and risk factors}

Prediction of other health outcomes

Seven of the studies used multimorbidity trajectories to predict subsequent health outcomes, ${ }^{31} 354345535556$ including self-reported health, cognitive ability, disability, medical utilisation and mortality (table 6). Among older adults, results showed that an increase in multimorbidity over 10 years was associated with worse reported health ${ }^{43}$ and that those who developed multimorbidity faster had greater risk of disability. ${ }^{31}$ In one study, changes in multimorbidity were found to be more predictive of mortality than baseline multimorbidity. ${ }^{35}$ By contrast, another 
Table 6 Summary of association analysis for health outcomes related to longitudinal multimorbidity trajectories

\begin{tabular}{lll} 
Study, year & Outcome investigated & Findings of association analysis \\
\hline $\begin{array}{l}\text { Calderón- } \\
\text { Larrañaga et al, }\end{array}$ & Disability & $\begin{array}{l}\text { The speed of multimorbidity is a strong predictor for disability in older adults, } \\
\text { even when accounting for baseline number of chronic conditions. }\end{array}$
\end{tabular}

$2018^{31}$

Chang et al, $2011^{53}$ Medical utilisation

Morbidity strata predicted medical utilisation as usefully as more complex risk adjusters.

\begin{tabular}{|c|c|c|}
\hline $\begin{array}{l}\text { Fraccaro et al, } \\
2016^{35}\end{array}$ & Mortality & $\begin{array}{l}\text { Change over time of Charlson Comorbidity Index }(\mathrm{CCl}) \text { was a stronger predictor } \\
\text { of mortality than baseline } \mathrm{CCl} \text {. }\end{array}$ \\
\hline Fabbri et al, $2016^{45}$ & $\begin{array}{l}\text { Standardised } \\
\text { neurocognitive tests }\end{array}$ & $\begin{array}{l}\text { Accumulation of multimorbidity was associated with faster decline in verbal } \\
\text { fluency but seems to have no effect on memory decline, in older adults without } \\
\text { mild cognitive impairment or dementia. }\end{array}$ \\
\hline Kim et al, $2018^{56}$ & Mortality & $\begin{array}{l}\text { The 'consistently high' multimorbidity trajectory group had the highest risk of } \\
\text { mortality at 1-year, 3-year and 5-year follow-ups. }\end{array}$ \\
\hline Zhu et al, $2018^{55}$ & Life expectancy & $\begin{array}{l}\text { Diabetes, plus hypertension plus complications reduced life expectancy the } \\
\text { most. The earlier the onset of multimorbidity, the greater the reduction in life. }\end{array}$ \\
\hline
\end{tabular}

study confirmed that a change in CCI predicts mortality but not necessarily better than a cross-sectional estimate of multimorbidity. ${ }^{43} \mathrm{Zhu}$ et $a \bar{e}^{55}$ found that earlier development of chronic conditions and earlier complications incur greater life-years lost. Finally, multimorbidity accumulation (as a marker of physical health deterioration) predicted faster decline in verbal fluency in older adults without cognitive impairment or dementia. ${ }^{45}$

\section{Risk factors for multimorbidity}

Nineteen of theselectedarticles $232527-3032-343740-42464749505457$ investigated risk factors for multimorbidity trajectories (table 7). Increasing age, although often accounted for in analyses, emerged as a dominant risk factor for acquisition, worsening or progression of multimorbidity. ${ }^{29} 42$ As expected, younger age groups were more likely to belong to a non-chronic healthier cluster. ${ }^{28}$ However, trajectories starting with depression were more prevalent in younger individuals. ${ }^{23}$ Younger cohorts were also found to be more likely to develop multimorbidity and to do so at a younger age. ${ }^{40}$ A few studies reported gender differences, with conflicting results. While one study found that those in the 'multiple risks' group were more likely to be female, ${ }^{54}$ another two studies found that men were more likely to transition between disease states than women. ${ }^{30} 41$

Four studies investigated ethnic variations. ${ }^{23} 414950$ In two US studies, compared with non-Hispanic whites, black Americans had a higher rate of multimorbidity at baseline along with a slower rate of disease accumulation over time, while Hispanic participants tended to start with fewer diseases and increase more rapidly. ${ }^{49} 50$ Different ethnicities also had different disease transition patterns. In the USA, white individuals were more likely to transition from ischaemic heart disease to death, while
Asian and Native Hawaiian and Pacific Islander individuals were more likely to transition from diabetes to diabetes plus chronic kidney disease. ${ }^{41}$ In the UK, diseasespecific sequences also differed by ethnicity: for example, the white ethnic group was dominated by depression as a starting point, while diabetes was the most common starting point in the black ethnic group. ${ }^{23}$

The studies also explored a range of sociodemographic determinants including area-based deprivation, education, occupation, income and marital status. Results largely confirm those found with cross-sectional analyses, with lower SES associated with worse multimorbidity trajectories. For example, lower levels of education were associated with higher rate of multimorbidity accumulation $^{33}{ }^{42}$ or worse multimorbidity trajectories. ${ }^{47}$ People living in more deprived areas were more likely to be in an evolving or multichronic multimorbidity cluster ${ }^{28}$ and to have trajectories with diabetes and depression as the most

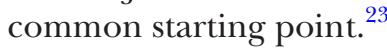

Health and health behaviours also showed associations. A Chinese study showed that a greater consumption of fruits, vegetables and grain slowed the development of multimorbidity. ${ }^{57}$ Alcohol consumption, smoking and physical inactivity were associated with worse multimorbidity trajectory patterns. ${ }^{30} 4247$ Physical function (measured by gait speed and grip strength at baseline) was associated with development and worsening of multimorbidity over 2 years in a sample of adults aged 50 years and over. ${ }^{29}$ Being overweight or obese was also associated with developing or worsening multimorbidity trajectory. $^{29} 4247$ Two studies investigated the role of specific biomarkers, finding that chronic inflammation, system dysregulation and multisystem failure are associated with 
Table 7 Summary of association analysis for risk factors related to multimorbidity trajectories

\begin{tabular}{lll}
\hline Study, year & Risk factors & Findings of association analysis \\
\hline $\begin{array}{l}\text { Ashworth et al, } \\
2019^{23}\end{array}$ & $\begin{array}{l}\text { Age, ethnicity and } \\
\text { deprivation }\end{array}$ & $\begin{array}{l}\text { Trajectories varied by age, ethnicity and deprivation. Depression as a starting point } \\
\text { was more common in younger, more deprived and white ethnic group. }\end{array}$ \\
$\begin{array}{l}\text { Caldeón- } \\
\text { Larrañaga et al, } \\
2019^{32}\end{array}$ & $\begin{array}{l}\text { Attitude towards life } \\
\text { and health }\end{array}$ & $\begin{array}{l}\text { Better attitudes towards life and health were associated with slower multimorbidity } \\
\text { development, independent of demographic, clinical, social, personality and lifestyle } \\
\text { factors. }\end{array}$
\end{tabular}

Canizares et al, Birth cohort $2017^{40}$

In each succeeding cohort, multimorbidity rates was higher and multimorbidity emerged earlier. Differences persisted independently of the risk factors for multimorbidity and period effect.

Dekhtyar et al, $2019^{33}$

Elementary education (early adulthood), lifelong active occupation (midadulthood), social network (later life)

Adults over 60 years old with higher than elementary education, lifelong active occupations and richer social networks had slower multimorbidity accumulation. The association between childhood circumstances and multimorbidity accumulation was attenuated by subsequent (mid and late) life experiences. Rich social networks reduced the speed of disease accumulation irrespective of lifelong job stress and level of education.

$\begin{array}{ll}\text { Fabbri et al, } & \text { Biomarkers: IL-6, IL- } \\ 2015^{34} & \text { 1ra, TNF- } \alpha \text { receptor } \\ & \text { II, and DHEAS (as } \\ & \text { a marker of chronic } \\ & \text { inflammation and } \\ & \text { system dysregulation) } \\ \text { Freisling et al, } & \text { Sex, age, healthy } \\ 2020^{30} & \text { lifestyle (healthy } \\ & \text { lifestyle index): diet } \\ & \text { (Mediterranean Diet } \\ & \text { Score), alcohol, } \\ & \text { smoking status and } \\ & \text { duration, physical } \\ & \text { activity (Cambridge } \\ \text { index) and BMI. } & \text { Education, } \\ & \text { menopausal status, } \\ \text { use of hormones } & \text { for postmenopausal } \\ \text { women. }\end{array}$

\begin{tabular}{|c|c|c|}
\hline $\begin{array}{l}\text { Hanson et al, } \\
2015^{46}\end{array}$ & $\begin{array}{l}\text { Parity, timing of } \\
\text { childbearing, birth } \\
\text { outcomes of offspring }\end{array}$ & $\begin{array}{l}\text { High parity, early childbearing and adverse offspring birth outcomes are associated } \\
\text { with particular later-life comorbidity patterns and trajectories, when controlling for } \\
\text { early-life conditions (age at parental death, childhood socioeconomic status, familial } \\
\text { excess longevity and religious participation). }\end{array}$ \\
\hline $\begin{array}{l}\text { Hiyoshi et al, } \\
2017^{37}\end{array}$ & $\begin{array}{l}\text { Income and marital } \\
\text { status }\end{array}$ & $\begin{array}{l}\text { Income and physical, cognitive and psychological function were associated with } \\
\text { trajectory group membership in unadjusted analysis but not in fully adjusted } \\
\text { analysis. }\end{array}$ \\
\hline Hsu, $2015^{54}$ & $\begin{array}{l}\text { Gender, education, } \\
\text { physical function, } \\
\text { depressive } \\
\text { symptoms, life } \\
\text { satisfaction, number } \\
\text { of health examination, } \\
\text { smoking and drinking. }\end{array}$ & $\begin{array}{l}\text { Those in the 'multiple risks' group were more likely to be female, less educated, } \\
\text { with more physical function difficulties, more depressive symptoms, lower life } \\
\text { satisfaction, more health examinations and not to smoke or drink. Members in } \\
\text { the 'CVD risk only' and 'multiple risks' groups were more likely to have physical } \\
\text { function difficulties and depressive symptoms. }\end{array}$ \\
\hline $\begin{array}{l}\text { Jackson et al, } \\
2015^{47}\end{array}$ & $\begin{array}{l}\text { Overweight or } \\
\text { obesity, education, } \\
\text { difficulty managing } \\
\text { income, smoking } \\
\text { alcohol consumption } \\
\text { and physical activity }\end{array}$ & $\begin{array}{l}\text { Being overweight or obese, having a lower education level and difficulty managing } \\
\text { on income associated with belonging to an accumulation trajectory. Smoking, } \\
\text { alcohol intake and physical activity level also appeared to be important risk factors } \\
\text { for the development of some trajectories. }\end{array}$ \\
\hline
\end{tabular}

Multimorbidity development with age was not linear, and significantly accelerated at older ages. Higher IL-6, IL-1ra and TNF- $\alpha$ receptor II and low DHEAS were associated with higher multimorbidity at baseline, independent of age, sex, BMI and education. Higher IL- 6 and steeper increase in IL-6 predicted an accelerated rise in multimorbidity over 9 years of follow-up.

Healthy lifestyle habits were strongly associated with lower incident multimorbidity of cancer and cardiometabolic diseases

The risk of transitioning to multimorbidity after having developed a first of the three chronic diseases was higher in men than in women. 
Table 7 Continued

\begin{tabular}{|c|c|c|}
\hline Study, year & Risk factors & Findings of association analysis \\
\hline $\begin{array}{l}\text { Lappenschaar et } \\
\text { al, } 2013^{25}\end{array}$ & $\begin{array}{l}\text { Urbanisation, } \\
\text { multimorbidity at } \\
\text { baseline }\end{array}$ & $\begin{array}{l}\text { Urbanisation level of a general practice is associated with the higher cumulative } \\
\text { incidence of chronic cardiovascular conditions, in particular obesity, hypertension, } \\
\text { dyslipidaemia, diabetes mellitus and ischaemic heart disease. Disease } \\
\text { accumulation rate higher when multimorbidity is already present at baseline. }\end{array}$ \\
\hline Perez et al, $2020^{27}$ & $\begin{array}{l}\text { Total serum } \\
\text { glutathione } \\
\text { (biomarker of } \\
\text { multisystem failure) }\end{array}$ & $\begin{array}{l}\text { Lower baseline levels of total serum glutathione were associated with a higher rate } \\
\text { of multimorbidity development, independent of covariates. }\end{array}$ \\
\hline $\begin{array}{l}\text { Quñones et al, } \\
2011^{50}\end{array}$ & Race/ethnicity & $\begin{array}{l}\text { White Americans differ from black and Mexican Americans in terms of level and rate } \\
\text { of change of multimorbidity. Mexican Americans demonstrate lower initial levels } \\
\text { and slower accumulation of comorbidities relative to white American. In contrast, } \\
\text { black Americans showed an elevated level of multimorbidity throughout the 11- } \\
\text { year period of observation, although their rate of change slowed relative to white } \\
\text { Americans. }\end{array}$ \\
\hline Ruel et al, $2014^{57}$ & Dietary patterns & $\begin{array}{l}\text { Greater amount of fruits and vegetables and grain (other than rice and wheat) } \\
\text { associated with reduced accumulation of multimorbidity. }\end{array}$ \\
\hline Ryan et al, $2018^{29}$ & $\begin{array}{l}\text { Multimorbidity at } \\
\text { baseline, age, obesity, } \\
\text { gait speed and grip } \\
\text { strength and access } \\
\text { to government } \\
\text { funded primary care. }\end{array}$ & $\begin{array}{l}\text { In non-multimorbid participants age, obesity, gait speed and grip strength were } \\
\text { significantly associated with development of multimorbidity. Age, access to } \\
\text { government funded primary care, gait speed and grip strength were significantly } \\
\text { associated with worsening of multimorbidity in those with multimorbidity. Gait } \\
\text { speed and age were significantly associated with new condition development in } \\
\text { people with complex multimorbidity. } \\
\text { (Overall) Gait speed, grip strength and age were significantly associated with } \\
\text { both the development of multimorbidity and accrual of additional conditions with } \\
\text { evidence of a dose--esponse relationship. }\end{array}$ \\
\hline Xu et al, $2018^{42}$ & $\begin{array}{l}\text { Sex, age, marital } \\
\text { status, income, } \\
\text { education, obesity, } \\
\text { physical activity, } \\
\text { smoking and } \\
\text { immigrant status. }\end{array}$ & $\begin{array}{l}\text { Odds of multimorbidity progression increased over time and with age. Women } \\
\text { with stroke were more likely to progress to another disease and become } \\
\text { multimorbid than other baseline characteristics. In adjusted models, accumulation } \\
\text { of multimorbidity was associated with non-married status, low income, lower } \\
\text { education, obesity, sedentary and smoking, and immigrant status. Obesity } \\
\text { differently associated with different sequences. }\end{array}$ \\
\hline
\end{tabular}

BMI, body mass index; CVD, cardiovascular disease; IL-6, interleukin 6; TNF- $\alpha$, tumour necrosis factor.

faster rate of multimorbidity accumulation. ${ }^{27}$ There were associations with family factors: being married was found to be protective of greater multimorbidity accumulation, ${ }^{37} 54$ and young parenthood (younger than 25 years) and extremely high parity (nine of more births) significant risk factors. ${ }^{46}$ Finally, a negative attitude towards life and health such as low life satisfaction and negative health outlook was associated with poorer multimorbidity trajectories. $^{32}$

\section{DISCUSSION}

Understanding longitudinal multimorbidity trajectories is an important public health priority for clinicians, academics and funders alike. ${ }^{4}$ This review aimed to take a systematic approach to scope existing research in the field with a focus on summarising commonly used methodological approaches and substantive findings. In doing so, we provide, to our knowledge, the first review to address longitudinal studies of multimorbidity, in a field 
saturated by cross-sectional research. ${ }^{212} 1558$ A strength of this review is the systematic and robust approach taken to searching and screening articles for inclusion and reviewing the selected studies, which should limit selection and extraction bias. We used predefined search terms, inclusion criteria and data extraction tools, and we engaged in double screening and extraction. ${ }^{22}$ The scoping review process meant that we summarised a wide variety of evidence, and therefore, it was not possible to perform a meta-analysis or use a standardised critical appraisal tool. Nevertheless, we provide a narrative-style critical summary of the selected articles. The results demonstrate that despite widespread expressed interest, relatively few studies do take a longitudinal approach to multimorbidity. All the studies included were published within the last decade and the vast majority using data from high-income countries. The studies showed a great variability in sampling strategy, ways of measuring multimorbidity and statistical approaches to characterising multimorbidity longitudinally. Methods for identifying longitudinal patterns ranged from counts of diseases to cluster or group-based analyses, to modelling transitions between diseases or disease sequences, and these were differentially useful for modelling accumulation, sequencing, clusters or transitions. From a substantive perspective, the studies showed associations with adverse outcomes such as worse reported health, greater risk of disability and mortality that we might expect based on the existing cross-sectional research. A range of multimorbidity trajectory risk factors were also identified, including sociodemographic factors, health behaviours, physical function, biomarkers, marriage and fertility factors, and attitudinal factors.

A limitation of narrative reviews is that they might select evidence to support a particular stance and do not necessarily take enough steps to eliminate selection bias. However, we selected a comprehensive set of items to extract before starting the review, and we engaged in double screening and extraction. Therefore, our methodological approach should limit selection and extraction bias. Our review did not engage in a critical appraisal of the quality of the selected studies. However, when the aim of a scoping review is to provide an overview of evidence (as ours was), methodological limitations and risk of bias of the evidence are not necessarily relevant and generally not performed. ${ }^{18}$

The review has highlighted some geographical bias in the distribution of multimorbidity research. In particular, there was an under-representation of longitudinal multimorbidity research in low-income and middle-income countries (LMICs), which likely reflects the geographical focus of multimorbidity research more generally. ${ }^{59}$ This may be due to underinvestment in multimorbidity research in LMICs, coupled with challenges of collecting or accessing relevant data. For example, most of the selected studies used electronic medical records or largescale longitudinal surveys, which are rare in developing countries. Nevertheless, due to the population ageing trends in LMICs, multimorbidity is already a major public health issue, with potentially more complex comorbidity patterns (eg, undiagnosed conditions or interactions with infectious disease), which deserve research using a longitudinal approach. Recently, published work in LMICs countries has tended to employ a cross-sectional design to analyse multimorbidity ${ }^{6-63}$ and therefore were not eligible for inclusion in this review. In addition, none of the studies in the review made cross-country comparisons, which may help to generate stronger evidence about disease trajectories and mechanisms involved in multimorbidity development and progression. For example, comparable cross-country patterns may suggest common biological mechanisms, whereas divergent findings could suggest moderation or prevention of disease processes by policy approaches to treatment, healthcare settings and institutional structures.

The selected studies used a great variety of data sources including administrative data (primary and secondary care data, health insurance claim data, patient and disease registries) and survey data, leading to variations in sample size and issues of generalisability. Issues of small sample size were only discussed in a limited number of studies, mostly in relation to subgroups such as ethnic minorities. ${ }^{23414950}$ Despite the use of large surveys or administrative data, the majority of studies expressed doubts about the generalisability of their findings. For example, welleducated and wealthy individuals were reported as overrepresented in longitudinal survey samples. ${ }^{27} 29$ 31-33 4247 Studies using administrative data sources typically investigated multimorbidity based on complete follow-up and excluding those who died, generating immortal time bias and investigating potentially healthier populations. ${ }^{39} 53$ In other studies, the choice of data sources themselves induced bias, for example, where samples were based on health service users. ${ }^{35} 48$ Others explained their sample might be representative but only of a particular group in a specific region $\left(\mathrm{eg}, \mathrm{Utah}^{46}\right)$. Another issue of generalisability, mentioned in previous reviews, ${ }^{15}$ was related to the heterogenous multimorbidity measures used. ${ }^{64} \mathrm{~A}$ wide variety of different diseases were included, and only a few studies used 'standard' measurement of multimorbidity like the Charlson ${ }^{20}$ or Elixhauser ${ }^{21}$ indices. Due to the diversity of data sources, diseases were ascertained in multiple ways, using clinical diagnosis, laboratory results, medication use and self-report. The only common measurement feature was that studies in this review tended not to define multimorbidity as the presence or two or more diseases.

The choice of statistical methods served to highlight or obscure different aspects of multimorbidity. For example, the most common approach, multilevel or single-level regression modelling, emphasises accumulation, providing the opportunity to simultaneously evaluate the baseline level of multimorbidity and the (slope) change in multimorbidity and how this differs between groups with different characteristics. However, it tends to obscure the role of specific diseases by collapsing all 
morbidity in a single count or index, and we cannot tell, for example, whether this faster accumulation is predominantly occurring among certain types of disorders. Complementary to regression approaches, groupedbased methodologies aimed to classify individuals into types of multimorbidity accumulation. A minority of studies employed the cluster-based approach to understand how specific diseases co-occur over time, ${ }^{48} 54$ which extends cross-sectional approaches often referred to as associative multimorbidity. ${ }^{11}$ This has the advantage of providing a more detailed understanding of the constellation of diseases that contribute to distinct trajectories, but due to the rarity of some diseases, will tend to find only highly prevalent clusters and is not suitable for rarer disease trajectories.

Some studies conceptualised longitudinal multimorbidity as transitioning between different disease states, using either structured Markov frameworks, ${ }^{44}$ multistate modelling ${ }^{26}{ }^{41}$ or a more data-driven, unsupervised approaches. ${ }^{24} 38$ The former, more structured approach to disease transition tended to provide a very detailed understanding of interactions between a small set of diseases, which can provide useful evidence for targeting prevention at those with the first disease, a risk stratification approach. The latter, data-driven approaches provide very comprehensive evidence for population-based strategies but relies on large datasets collected over a number of years and appropriate clinical expertise to interpret the results of patterns identified through artificial intelligence (AI). Given the growing interdisciplinary collaborations between epidemiology and computer science, data-driven research will continue to expand in the coming years and extend to prediction modelling and projections. One of the strengths of computer science, and the recent new developments in AI with machine learning, is the ability to work towards solutions that can combine prediction models and compare different treatment options for cohorts of patients (eg, what is the likelihood that a medication commonly used for one chronic condition may speed up the progression of another condition or lead to the development of a new condition).

Compared with cross-sectional studies, longitudinal approaches provide more detailed insight about the role of specific risk factors. For example, while age is a known risk factor, this review highlights how older individuals, once multimorbid, show acceleration of multimorbidity. ${ }^{29}$ Multimorbidity trajectory patterns varied by ethnicity, ${ }^{23414950}$ marital status, ${ }^{37} 42$ educational level and area-level deprivation, ${ }^{28} 334247$ confirming some patterns observed in cross-sectional data. A useful exploitation of longitudinal data-not included in these studies-would be to explore how change in risk factors such as SES or marital status influences different multimorbidity trajectories, which may help identify at-risk groups and target prevention strategies. As highlighted by Zhu and colleagues, ${ }^{55}$ the earlier the multimorbidity onset in the life course, the greater the life year lost for that individual. Therefore, future research should seek to take a life course approach in order to disentangle early preventable factors of multimorbidity onset but also to determine later life factors influencing additional disease accumulation. Risk factors should be considered at the level of the individual (life course and contemporaneous factors), medication use and the wider social environment, including poor environmental conditions, and interaction with institutional structures (eg, healthcare system organisation). The increasing availability of 'big data', which links longitudinal administrative data on individuals with health, and geospatial data will make these holistic approaches technically possible. Future research should focus on generating the knowledge required to develop interventions aimed at preventing both the onset and the worsening of multimorbidity.

\section{CONCLUSION}

This review identifies a small but developing body of literature attempting to describe multimorbidity longitudinally. There was a notable lack of studies in LMICs, as well exploring minority ethnic groups. A wide variety of complementary methods are employed, emphasising factors associated with greater disease accumulation, speed of accumulation and specific disease transition processes. Methodologies based on disease ordering or sequence was seldom explored by the studies, and while it is challenging to identify exact timing of disease, future research could seek to investigate disease sequencing that underlies the accumulation process. Risk factors for trajectory types could inform future intervention and prevention strategies at critical life course periods and disease progression turning points. Initiatives to enable researchers greater access to relevant data sources, such as the HDR UK initiative to harmonise datasets for multimorbidity research, is crucial and should become more generalised in order to gain the insight on multimorbidity processes required to feed into prevention and policy makers strategies at a global scale.

Acknowledgements We would like to thank Iris Ho and Bruce Guthrie for providing additional references that our systematic search might have missed.

Contributors GC and CTM participated in the screening, data extraction and analysis and helped draft the manuscript. FS and JKFB helped draft the manuscript. KK acquired the funding, conceptualised the study, participated in the screening, data extraction and analysis, helped draft the manuscript and acts as the guarantor for the study. All authors approved the final version for submission.

Funding This work was supported by the Academy of Medical Sciences, the Wellcome Trust, the Government Department of Business, Energy and Industrial Strategy, the British Heart Foundation Diabetes UK, and the Global Challenges Research Fund (Grant number SBF004\1093 awarded to KK).

Disclaimer The funders had no input to the design or execution of the study. Competing interests None declared.

Patient consent for publication Not applicable.

Provenance and peer review Not commissioned; externally peer reviewed. 
Data availability statement Data sharing not applicable as no datasets generated and/or analysed for this study.

Supplemental material This content has been supplied by the author(s). It has not been vetted by BMJ Publishing Group Limited (BMJ) and may not have been peer-reviewed. Any opinions or recommendations discussed are solely those of the author(s) and are not endorsed by BMJ. BMJ disclaims all liability and responsibility arising from any reliance placed on the content. Where the content includes any translated material, BMJ does not warrant the accuracy and reliability of the translations (including but not limited to local regulations, clinical guidelines, terminology, drug names and drug dosages), and is not responsible for any error and/or omissions arising from translation and adaptation or otherwise.

Open access This is an open access article distributed in accordance with the Creative Commons Attribution 4.0 Unported (CC BY 4.0) license, which permits others to copy, redistribute, remix, transform and build upon this work for any purpose, provided the original work is properly cited, a link to the licence is given, and indication of whether changes were made. See: https://creativecommons.org/ licenses/by/4.0/.

\section{ORCID iDs}

Genevieve Cezard http://orcid.org/0000-0002-3011-7416

Calum Thomas McHale http://orcid.org/0000-0002-9274-7261

Katherine Keenan http://orcid.org/0000-0002-9670-1607

\section{REFERENCES}

1 Diederichs C, Berger K, Bartels DB. The measurement of multiple chronic diseases-a systematic review on existing multimorbidity indices. J Gerontol A Biol Sci Med Sci 2011;66:301-11.

2 Johnston MC, Crilly M, Black C, et al. Defining and measuring multimorbidity: a systematic review of systematic reviews. Eur J Public Health 2019;29:182-9.

3 Hajat C, Stein E. The global burden of multiple chronic conditions: a narrative review. Preventive Medicine Reports 2018;12:284-93.

4 Academy of Medical Sciences. Multimorbidity: a priority for global health research. London, 2018. Available: https://acmedsci.ac.uk/ file-download/82222577

5 Kingston A, Robinson L, Booth $\mathrm{H}$, et al. Projections of multimorbidity in the older population in England to 2035: estimates from the population ageing and care simulation (PACSim) model. Age Ageing 2018;47:374-80.

6 Makovski TT, Schmitz S, Zeegers MP, et al. Multimorbidity and quality of life: systematic literature review and meta-analysis. Ageing Res Rev 2019;53:100903.

7 Ryan A, Wallace E, O'Hara P, et al. Multimorbidity and functional decline in community-dwelling adults: a systematic review. Health Qual Life Outcomes 2015;13:1-13.

8 Nunes BP, Flores TR, Mielke Gl, et al. Multimorbidity and mortality in older adults: a systematic review and meta-analysis. Arch Gerontol Geriatr 2016:67:130-8

9 Wang L, Si L, Cocker F, et al. A systematic review of cost-ofillness studies of multimorbidity. Appl Health Econ Health Policy 2018;16:15-29.

10 SK N, Tawiah R, Sawyer M. Patterns of multimorbid health conditions: a systematic review of analytical methods and comparison analysis. Int J Epidemiol 2018;47:1687-704.

11 Prados-Torres A, Calderón-Larrañaga A, Hancco-Saavedra J, et al. Multimorbidity patterns: a systematic review. J Clin Epidemiol 2014;67:254-66.

12 Violan C, Foguet-Boreu Q, Flores-Mateo G, et al. Prevalence, determinants and patterns of multimorbidity in primary care: a systematic review of observational studies. PLoS One 2014;9:e102149.

13 Pathirana TI, Jackson CA. Socioeconomic status and multimorbidity: a systematic review and meta-analysis. Aust N Z J Public Health 2018;42:186-94.

14 Fortin M, Haggerty J, Almirall J, et al. Lifestyle factors and multimorbidity: a cross sectional study. BMC Public Health 2014:14:1-8.

$15 \mathrm{Xu}$ X, Mishra GD, Jones M. Mapping the global research landscape and knowledge gaps on multimorbidity: a bibliometric study. J Glob Health 2017;7:010414.

16 Moher D, Stewart L, Shekelle P. All in the family: systematic reviews, rapid reviews, scoping reviews, realist reviews, and more. Syst Rev 2015;4:183.

17 Munn Z, Peters MDJ, Stern C, et al. Systematic review or scoping review? guidance for authors when choosing between a systematic or scoping review approach. BMC Med Res Methodol 2018;18:1-7.
18 Peters MDJ, Godfrey CM, Khalil H, et al. Guidance for conducting systematic scoping reviews. Int J Evid Based Healthc 2015;13:141-6.

19 Tricco AC, Lillie E, Zarin W, et al. PRISMA extension for scoping reviews (PRISMA-ScR): checklist and explanation. Ann Intern Med 2018;169:467-73.

20 Charlson ME, Pompei P, Ales KL, et al. A new method of classifying prognostic comorbidity in longitudinal studies: development and validation. J Chronic Dis 1987;40:373-83.

21 Elixhauser A, Steiner C, Harris DR, et al. Comorbidity measures for use with administrative data. Med Care 1998;36:8-27.

22 Buscemi N, Hartling L, Vandermeer B, et al. Single data extraction generated more errors than double data extraction in systematic reviews. J Clin Epidemiol 2006;59:697-703.

23 Ashworth M, Durbaba S, Whitney D, et al. Journey to multimorbidity: longitudinal analysis exploring cardiovascular risk factors and sociodemographic determinants in an urban setting. BMJ Open 2019;9:e031649.

24 Beck MK, Jensen AB, Nielsen AB, et al. Diagnosis trajectories of prior multi-morbidity predict sepsis mortality. Sci Rep 2016;6:1-9.

25 Lappenschaar M, Hommersom A, Lucas PJF, et al. Multilevel temporal Bayesian networks can model longitudinal change in multimorbidity. J Clin Epidemiol 2013;66:1405-16.

26 Lindhagen L, Van Hemelrijck M, Robinson D, et al. How to model temporal changes in comorbidity for cancer patients using prospective cohort data. BMC Med Inform Decis Mak 2015;15:96.

27 Pérez LM, Hooshmand B, Mangialasche F, et al. Glutathione serum levels and rate of multimorbidity development in older adults. Journals Gerontol Ser A 2020;75:1089-94.

28 Strauss VY, Jones PW, Kadam UT, et al. Distinct trajectories of multimorbidity in primary care were identified using latent class growth analysis. J Clin Epidemiol 2014;67:1163-71.

29 Ryan A, Murphy C, Boland F, et al. What is the impact of physical activity and physical function on the development of multimorbidity in older adults over time? a population-based cohort study. Journals Gerontol Ser A 2018;73:1538-44.

30 Freisling $\mathrm{H}$, Viallon $\mathrm{V}$, Lennon $\mathrm{H}$, et al. Lifestyle factors and risk of multimorbidity of cancer and cardiometabolic diseases: a multinational cohort study. BMC Med 2020;18:1-11.

31 Calderón-Larrañaga A, Santoni G, Wang HX, et al. Rapidly developing multimorbidity and disability in older adults: does social background matter? J Intern Med 2018;283:489-99.

32 Calderón-Larrañaga A, Vetrano DL, Welmer A-K, et al. Psychological correlates of multimorbidity and disability accumulation in older adults. Age Ageing 2019;48:789-96.

33 Dekhtyar S, Vetrano DL, Marengoni A, et al. Association between speed of multimorbidity accumulation in old age and life experiences: a cohort study. Am J Epidemiol 2019;188:1627-36.

34 Fabbri E, An Y, Zoli M, et al. Aging and the burden of multimorbidity: associations with inflammatory and anabolic hormonal biomarkers. Journals Gerontol Ser A 2015;70:63-70.

35 Fraccaro P, Kontopantelis E, Sperrin M. Predicting mortality from change-over-time in the Charlson comorbidity index: a retrospective cohort study in a data-intensive UK health system. Med 2016;95:e4973.

36 Gellert P, von Berenberg P, Oedekoven M, et al. Centenarians differ in their comorbidity trends during the 6 years before death compared to individuals who died in their $80 \mathrm{~S}$ or $90 \mathrm{~s}$. The Journals of Gerontology: Series A 2018;73:1357-62.

37 Hiyoshi A, Fall K, Bergh C, et al. Comorbidity trajectories in working age cancer survivors: a national study of Swedish men. Cancer Epidemiol 2017;48:48-55.

38 Jensen AB, Moseley PL, Oprea TI, et al. Temporal disease trajectories condensed from population-wide registry data covering 6.2 million patients. Nat Commun 2014;5

39 Faruqui SHA, Alaeddini A, Jaramillo CA, et al. Mining patterns of comorbidity evolution in patients with multiple chronic conditions using unsupervised multi-level temporal Bayesian network. PLoS One 2018;13:e0199768.

40 Canizares M, Hogg-Johnson S, Gignac MAM, et al. Increasing trajectories of multimorbidity over time: birth cohort differences and the role of changes in obesity and income. The Journals of Gerontology: Series B 2018;73:1303-14.

41 Siriwardhana C, Lim E, Davis J, et al. Progression of diabetes, ischemic heart disease, and chronic kidney disease in a three chronic conditions multistate model. BMC Public Health 2018;18:752

42 Xu X, Mishra GD, Dobson AJ, et al. Progression of diabetes, heart disease, and stroke multimorbidity in middle-aged women: a 20-year cohort study. PLoS Med 2018;15:e1002516.

43 Zeng C, Ellis JL, Steiner JF, et al. Assessment of morbidity over time in predicting health outcomes. Med Care 2014;52 Suppl 3:S52-9. 
44 Alaeddini A, Jaramillo CA, Faruqui SHA. Mining major transitions of chronic conditions in patients with multiple chronic conditions. Methods Inf Med 2017;56:391-400.

45 Fabbri E, An Y, Zoli M, et al. Association between accelerated multimorbidity and age-related cognitive decline in older Baltimore longitudinal study of aging participants without dementia. J Am Geriatr Soc 2016;64:965-72.

46 Hanson HA, Smith KR, Zimmer Z. Reproductive history and later-life comorbidity trajectories: a Medicare-Linked cohort study from the Utah population database. Demography 2015;52:2021-49.

47 Jackson CA, Dobson A, Tooth L, et al. Body mass index and socioeconomic position are associated with 9-year trajectories of multimorbidity: a population-based study. Prev Med 2015;81:92-8.

48 Pugh MJ, Finley EP, Wang C-P, et al. A retrospective cohort study of comorbidity trajectories associated with traumatic brain injury in veterans of the Iraq and Afghanistan wars. Brain Injury 2016;30:1481-90.

49 Quiñones AR, Botoseneanu A, Markwardt S, et al. Racial/Ethnic differences in multimorbidity development and chronic disease accumulation for middle-aged adults. PLoS One 2019;14:e0218462.

50 Quiñones AR, Liang J, Bennett JM, et al. How does the trajectory of multimorbidity vary across black, white, and Mexican Americans in middle and old age? J Gerontol B Psychol Sci Soc Sci 2011;66:739-49.

51 Rocca WA, Gazzuola-Rocca L, Smith CY, et al. Accelerated accumulation of multimorbidity after bilateral oophorectomy: a population-based cohort study. Mayo Clin Proc 2016;91:1577-89.

52 Ruel G, Lévesque J-F, Stocks N, et al. Understanding the evolution of multimorbidity: evidences from the North West Adelaide health longitudinal study (NWAHS). PLoS One 2014;9:e96291.

53 Chang HY, Clark JM, Weiner JP. Morbidity trajectories as predictors of utilization: Multi-year disease patterns in taiwan's national health insurance program. Med Care 2011;49:918-23.

$54 \mathrm{Hsu} \mathrm{H-C.} \mathrm{Trajectories} \mathrm{of} \mathrm{multimorbidity} \mathrm{and} \mathrm{impacts} \mathrm{on} \mathrm{successful}$ aging. Exp Gerontol 2015;66:32-8.

55 Zhu Z, Heng BH, Teow KL. Lifetime trajectory simulation of chronic disease progression and comorbidity development. J Biomed Inform 2018;88:29-36.
56 Kim J-H, Rhee Y, Lee Y. Longitudinal changes in comorbidity patterns over time in relation to mortality in older Korean adults. Arch Gerontol Geriatr 2018;79:63-8.

57 Ruel G, Shi Z, Zhen S, et al. Association between nutrition and the evolution of multimorbidity: the importance of fruits and vegetables and whole grain products. Clinical Nutrition 2014;33:513-20.

58 Nguyen H, Manolova G, Daskalopoulou C, et al. Prevalence of multimorbidity in community settings: a systematic review and meta-analysis of observational studies. J Comorb 2019;9:2235042X1987093.

59 Abebe F, Schneider M, Asrat B, et al. Multimorbidity of chronic non-communicable diseases in low- and middle-income countries: a scoping review. J Comorb 2020;10:2235042X2096191.

60 Bayes-Marin I, Sanchez-Niubo A, Egea-Cortés L, et al. Multimorbidity patterns in low-middle and high income regions: a multiregion latent class analysis using ATHLOS harmonised cohorts. BMJ Open 2020;10:34441.

61 Garin N, Koyanagi A, Chatterji S, et al. Global multimorbidity patterns: a cross-sectional, population-based, Multi-Country study. GERONA 2016;71:205-14.

62 Pati S, Swain S, Metsemakers J, et al. Pattern and severity of multimorbidity among patients attending primary care settings in Odisha, India. PLoS One 2017;12:e0183966.

63 Rivera-Almaraz A, Manrique-Espinoza B, Ávila-Funes JA, et al. Disability, quality of life and all-cause mortality in older Mexican adults: association with multimorbidity and frailty. BMC Geriatr 2018;18:1-9.

64 Stirland LE, González-Saavedra L, Mullin DS, et al. Measuring multimorbidity beyond counting diseases: systematic review of community and population studies and guide to index choice. BMJ 2020;12:m160.

65 Khan NF, Perera R, Harper S, et al. Adaptation and validation of the Charlson index for Read/OXMIS coded databases. BMC Fam Pract 2010;11.

66 Quan H, Sundararajan V, Halfon P, et al. Coding algorithms for defining comorbidities in ICD-9-CM and ICD-10 administrative data. Med Care 2005;43:1130-9. 


\section{Appendix A: Preferred Reporting Items for Systematic reviews and Meta-Analyses extension for Scoping Reviews (PRISMA-ScR) Checklist}

\begin{tabular}{|c|c|c|c|}
\hline SECTION & ITEM & PRISMA-ScR CHECKLIST ITEM & $\begin{array}{l}\text { REPORTED } \\
\text { ON PAGE \# }\end{array}$ \\
\hline \multicolumn{4}{|l|}{ TITLE } \\
\hline Title & 1 & Identify the report as a scoping review. & 1 \\
\hline \multicolumn{4}{|l|}{ ABSTRACT } \\
\hline $\begin{array}{l}\text { Structured } \\
\text { summary }\end{array}$ & 2 & $\begin{array}{l}\text { Provide a structured summary that includes (as } \\
\text { applicable): background, objectives, eligibility } \\
\text { criteria, sources of evidence, charting methods, } \\
\text { results, and conclusions that relate to the review } \\
\text { questions and objectives. }\end{array}$ & 2 \\
\hline \multicolumn{4}{|l|}{ INTRODUCTION } \\
\hline Rationale & 3 & $\begin{array}{l}\text { Describe the rationale for the review in the context } \\
\text { of what is already known. Explain why the review } \\
\text { questions/objectives lend themselves to a scoping } \\
\text { review approach. }\end{array}$ & $4-5$ \\
\hline Objectives & 4 & $\begin{array}{l}\text { Provide an explicit statement of the questions and } \\
\text { objectives being addressed with reference to their } \\
\text { key elements (e.g., population or participants, } \\
\text { concepts, and context) or other relevant key } \\
\text { elements used to conceptualize the review } \\
\text { questions and/or objectives. }\end{array}$ & -5 \\
\hline \multicolumn{4}{|c|}{ q } \\
\hline $\begin{array}{l}\text { Protocol and } \\
\text { registration }\end{array}$ & 5 & $\begin{array}{l}\text { Indicate whether a review protocol exists; state if } \\
\text { and where it can be accessed (e.g., a Web } \\
\text { address); and if available, provide registration } \\
\text { information, including the registration number. }\end{array}$ & $\mathrm{n} / \mathrm{a}$ \\
\hline Eligibility criteria & 6 & $\begin{array}{l}\text { Specify characteristics of the sources of evidence } \\
\text { used as eligibility criteria (e.g., years considered, } \\
\text { language, and publication status), and provide a } \\
\text { rationale. }\end{array}$ & 5 \\
\hline $\begin{array}{l}\text { Information } \\
\text { sources }^{*}\end{array}$ & 7 & $\begin{array}{l}\text { Describe all information sources in the search (e.g., } \\
\text { databases with dates of coverage and contact with } \\
\text { authors to identify additional sources), as well as } \\
\text { the date the most recent search was executed. }\end{array}$ & 7 (May 2020) \\
\hline Search & 8 & $\begin{array}{l}\text { Present the full electronic search strategy for at } \\
\text { least } 1 \text { database, including any limits used, such } \\
\text { that it could be repeated. }\end{array}$ & $\begin{array}{l}\text { Table } 2 \text { and } \\
\text { Appendix B }\end{array}$ \\
\hline $\begin{array}{l}\text { Selection of } \\
\text { sources of } \\
\text { evidence }\end{array}$ & 9 & $\begin{array}{l}\text { State the process for selecting sources of evidence } \\
\text { (i.e., screening and eligibility) included in the } \\
\text { scoping review. }\end{array}$ & $5-8$ \\
\hline $\begin{array}{l}\text { Data charting } \\
\text { process } \ddagger\end{array}$ & 10 & $\begin{array}{l}\text { Describe the methods of charting data from the } \\
\text { included sources of evidence (e.g., calibrated } \\
\text { forms or forms that have been tested by the team } \\
\text { before their use, and whether data charting was } \\
\text { done independently or in duplicate) and any } \\
\text { processes for obtaining and confirming data from } \\
\text { investigators. }\end{array}$ & 7 \\
\hline Data items & 11 & $\begin{array}{l}\text { List and define all variables for which data were } \\
\text { sought and any assumptions and simplifications } \\
\text { made. }\end{array}$ & $7-8$ \\
\hline $\begin{array}{l}\text { Critical appraisal } \\
\text { of individual } \\
\text { sources of } \\
\text { evidence }\end{array}$ & 12 & $\begin{array}{l}\text { If done, provide a rationale for conducting a critical } \\
\text { appraisal of included sources of evidence; describe } \\
\text { the methods used and how this information was } \\
\text { used in any data synthesis (if appropriate). }\end{array}$ & $\mathrm{n} / \mathrm{a}$ \\
\hline $\begin{array}{l}\text { Synthesis of } \\
\text { results }\end{array}$ & 13 & $\begin{array}{l}\text { Describe the methods of handling and summarizing } \\
\text { the data that were charted. }\end{array}$ & $7-8$ \\
\hline
\end{tabular}




\begin{tabular}{|c|c|c|c|}
\hline SECTION & ITEM & PRISMA-ScR CHECKLIST ITEM & $\begin{array}{l}\text { REPORTED } \\
\text { ON PAGE \# }\end{array}$ \\
\hline \multicolumn{4}{|l|}{ RESULTS } \\
\hline $\begin{array}{l}\text { Selection of } \\
\text { sources of } \\
\text { evidence }\end{array}$ & 14 & $\begin{array}{l}\text { Give numbers of sources of evidence screened, } \\
\text { assessed for eligibility, and included in the review, } \\
\text { with reasons for exclusions at each stage, ideally } \\
\text { using a flow diagram. }\end{array}$ & $\begin{array}{l}8 \text { and Figure } \\
1\end{array}$ \\
\hline $\begin{array}{l}\text { Characteristics of } \\
\text { sources of } \\
\text { evidence }\end{array}$ & 15 & $\begin{array}{l}\text { For each source of evidence, present } \\
\text { characteristics for which data were charted and } \\
\text { provide the citations. }\end{array}$ & 9 and Table 3 \\
\hline $\begin{array}{l}\text { Critical appraisal } \\
\text { within sources of } \\
\text { evidence }\end{array}$ & 16 & $\begin{array}{l}\text { If done, present data on critical appraisal of } \\
\text { included sources of evidence (see item 12). }\end{array}$ & $\mathrm{n} / \mathrm{a}$ \\
\hline $\begin{array}{l}\text { Results of } \\
\text { individual sources } \\
\text { of evidence }\end{array}$ & 17 & $\begin{array}{l}\text { For each included source of evidence, present the } \\
\text { relevant data that were charted that relate to the } \\
\text { review questions and objectives. }\end{array}$ & Tables $4,5,7$ \\
\hline $\begin{array}{l}\text { Synthesis of } \\
\text { results }\end{array}$ & 18 & $\begin{array}{l}\text { Summarize and/or present the charting results as } \\
\text { they relate to the review questions and objectives. }\end{array}$ & $12-23$ \\
\hline \multicolumn{4}{|l|}{ DISCUSSION } \\
\hline $\begin{array}{l}\text { Summary of } \\
\text { evidence }\end{array}$ & 19 & $\begin{array}{l}\text { Summarize the main results (including an overview } \\
\text { of concepts, themes, and types of evidence } \\
\text { available), link to the review questions and } \\
\text { objectives, and consider the relevance to key } \\
\text { groups. }\end{array}$ & $23-24$ \\
\hline Limitations & 20 & $\begin{array}{l}\text { Discuss the limitations of the scoping review } \\
\text { process. }\end{array}$ & 24 \\
\hline Conclusions & 21 & $\begin{array}{l}\text { Provide a general interpretation of the results with } \\
\text { respect to the review questions and objectives, as } \\
\text { well as potential implications and/or next steps. }\end{array}$ & $24-27$ \\
\hline \multicolumn{4}{|c|}{ 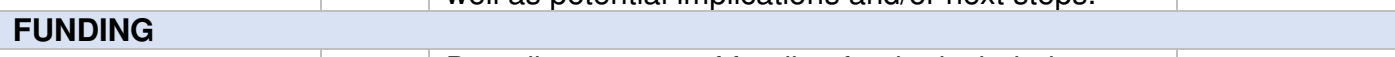 } \\
\hline Funding & 22 & $\begin{array}{l}\text { Describe sources of funding for the included } \\
\text { sources of evidence, as well as sources of funding } \\
\text { for the scoping review. Describe the role of the } \\
\text { funders of the scoping review. }\end{array}$ & 28 \\
\hline \multicolumn{4}{|c|}{$\begin{array}{l}\text { JBI = Joanna Briggs Institute; PRISMA-ScR = Preferred Reporting Items for Systematic reviews and Meta- } \\
\text { Analyses extension for Scoping Reviews. } \\
\text { * Where sources of evidence (see second footnote) are compiled from, such as bibliographic databases, social } \\
\text { media platforms, and Web sites. } \\
\text { † A more inclusive/heterogeneous term used to account for the different types of evidence or data sources (e.g., } \\
\text { quantitative and/or qualitative research, expert opinion, and policy documents) that may be eligible in a scoping } \\
\text { review as opposed to only studies. This is not to be confused with information sources (see first footnote). } \\
\text { † The frameworks by Arksey and O'Malley }(6) \text { and Levac and colleagues }(7) \text { and the JBI guidance }(4,5) \text { refer to } \\
\text { the process of data extraction in a scoping review as data charting. } \\
\S \text { The process of systematically examining research evidence to assess its validity, results, and relevance before } \\
\text { using it to inform a decision. This term is used for items } 12 \text { and } 19 \text { instead of "risk of bias" (which is more } \\
\text { applicable to systematic reviews of interventions) to include and acknowledge the various sources of evidence } \\
\text { that may be used in a scoping review (e.g., quantitative and/or qualitative research, expert opinion, and policy } \\
\text { document). }\end{array}$} \\
\hline
\end{tabular}




\section{Appendix B: Data Search Strategies}

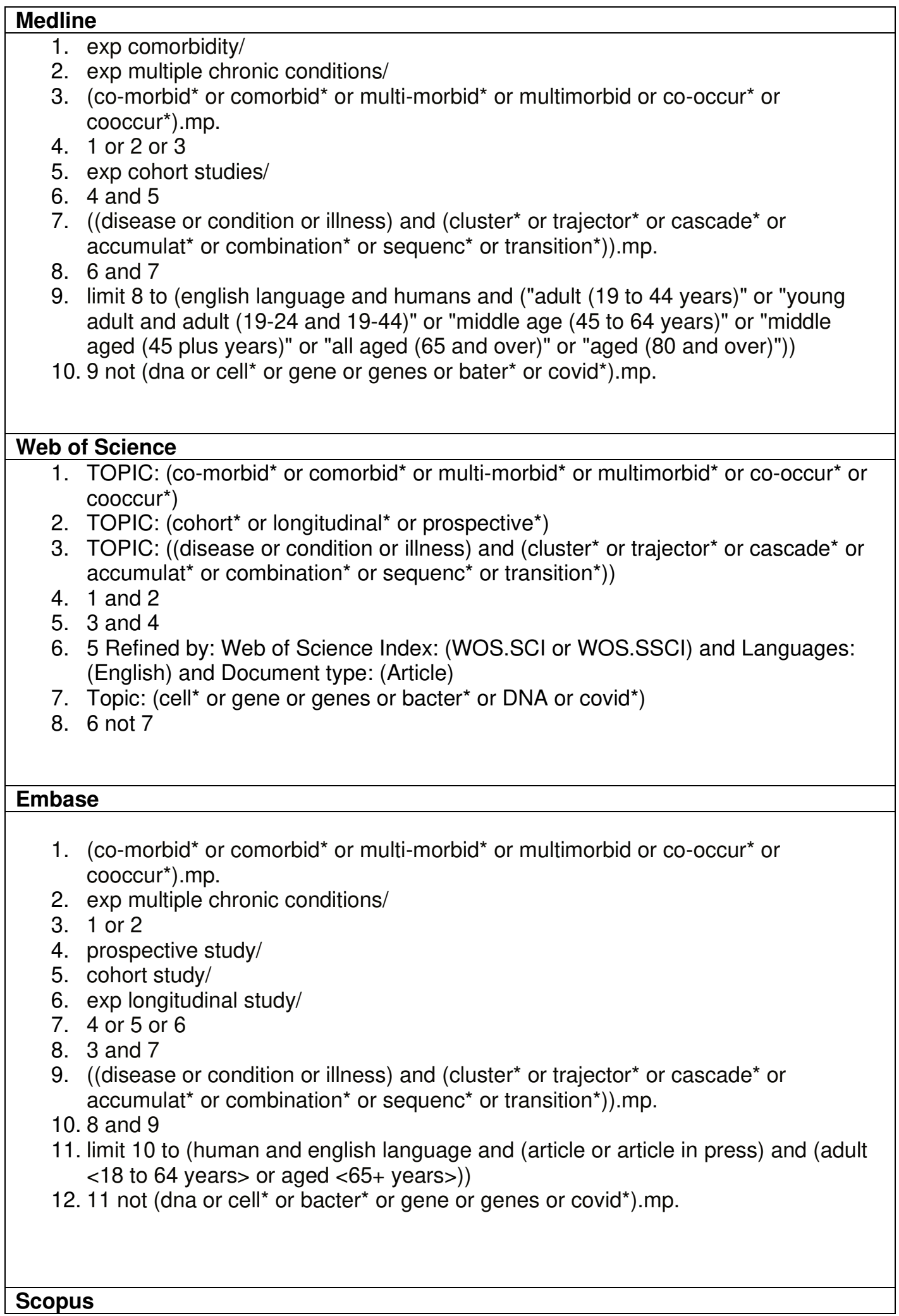


( ( TITLE-ABS-KEY ( co-morbid* OR comorbid* OR multimorbid* OR multimorbid* OR co-occur* OR cooccur*)) AND (TITLE-ABS-

KEY ( ( disease OR condition OR illness) AND ( cluster* OR trajector* OR cascade * OR accumulat* OR combination* OR sequenc* OR transition* $\left.{ }^{*}\right)$ ) ) AND ( TITLEABS-KEY ( cohort* OR longitudinal ${ }^{*}$ OR prospective* $)$ )) AND NOT ( TITLE-ABS KEY ( cell* OR gene OR genes OR bacter* OR dna OR covid*)) AND ( LIMITTO ( DOCTYPE, "ar") ) AND ( LIMIT-TO ( SUBJAREA, "MEDI") OR LIMITTO ( SUBJAREA, "PSYC" ) OR LIMIT-TO ( SUBJAREA, "NURS") OR LIMITTO ( SUBJAREA, "MULT") OR LIMIT-TO ( SUBJAREA, "HEAL") OR LIMITTO ( SUBJAREA, "SOCI" ) OR LIMIT-TO ( SUBJAREA, "COMP") OR LIMITTO ( SUBJAREA, "DECl") ) AND ( LIMIT-

TO ( EXACTKEYWORD, "Human" ) OR LIMIT-

TO ( EXACTKEYWORD, "Humans") ) AND ( LIMIT-

TO ( LANGUAGE, "English" )) AND ( LIMIT-TO ( SRCTYPE, "j" )) 


\section{Appendix C: List of conditions included in each selected study}

Study, year
Alaeddini et al. (2017)
Ashworth et al. (2019)
Beck et al. (2016)
Calderon-Larranaga et al. (2018)

Calderon-Larranaga et al. (2019)

Canizares et al. (2017)

Chang et al. (2011)

Dekhtyar et al. (2019)

Fabbri et al. (2015)

Fabbri et al. (2016)

Faruqui et al. (2018)

Fraccaro et al. (2016)

Freisling et al. (2020)

Gellert et al. (2018)

Hanson et al. (2015)

Hiyoshi et al. (2017)

Hsu (2015)

Jackson et al. (2015)

Jensen et al. (2014)

Kim et al. (2018)

Lappenschaar et al. (2013)
List of diseases or disease categories included if available

Back pain, hypertension, Post-Traumatic Stress Disorder (PTSD), and depression

Long-term conditions: atrial fibrillation, COPD, chronic pain, Chronic Kidney Disease (CKD), Coronary Heart Disease (CHD), Diabetes Mellitus (DM), dementia, depression, Heart Failure (HF), serious mental illness, stroke, and morbid obesity

All temporal trajectory of four diseases, identified from temporal directed pairs of diseases combined into longer trajectories of temporal consecutives diseases (three temporal disease pairs) with sepsis as the fourth disease, trajectory must be found for at least 20 patients following Jensen (2014) methodology

918 chronic conditions identified by an international team of geriatricians, general practitioners and epidemiologists. A condition was selected if defined as chronic and if it either worsened quality of life, residual disability remained or if long period of care, treatment or rehabilitation was required.

As specified by Calderon-Larranaga et al. (2018)

Chronic conditions: arthritis, back problems, asthma, allergies (excluding food allergies), bronchitis, emphysema, diabetes, high blood pressure, heart conditions, stroke, cancer, ulcers, urinary incontinency, dementia, migraine, glaucoma, and cataracts.

27 morbidity patterns grouped into 6 trajectory groups: constant high, constant medium, constant low, decreasing, increasing, and erratic.

As specified by Calderon-Larranaga et al. (2018)

Chronic conditions: hypertension, diabetes, ischemic heart disease, congestive heart failure, stroke, COPD, cancer, Parkinson's disease, hip fracture, lower extremities joint disease, anemia, chronic kidney disease, peripheral arterial disease, cognitive impairment, and depression.

Chronic diseases: hypertension, diabetes, ischemic heart disease, congestive heart failure, stroke, COPD, cancer, Parkinson's disease, hip fracture, lower extremities joint disease, anemia, chronic kidney disease, and peripheral arterial disease.

Traumatic brain injury (TBI), Post-Traumatic Stress Disorder (PTSD), depression, substance abuse, and back pain.

A list of 22 diseases of the $\mathrm{CCl}$ score is used but due to data restrictions on sexual and mental health, diseases such as HIV and dementia could not be included Cancer, CVD, Type 2 Diabetes

A list of 30 health conditions based on the Elixhauser multimorbidity index

A list of 17 conditions based on the Charlson comorbidity index: myocardial infarction, congestive heart failure, peripheral vascular disease, cerebrovascular disease, dementia, chronic pulmonary disease, rheumatologic disease, peptic ulcer disease, mild liver disease, diabetes (mild to moderate), diabetes with chronic complications, hemiplegia or paraplegia, renal kidney disease, any malignancy, moderate or severe liver disease, metastatic solid tumor, AIDS

List of diseases including some based on the Charlson Comorbidity Index: depression, anxiety, osteoporosis, and infectious disease

+ myocardial infarction, congestive heart failure, peripheral vascular disease, cerebrovascular disease, dementia, chronic pulmonary disease, rheumatologic disease, chronic renal failure, mild liver disease, diabetes with and without chronic complications, hemiplegia or paraplegia, renal disease, moderate or severe liver disease, and AIDS/HIV

Diseases were grouped into six disease types: CVD (including diabetes mellitus, heart disease, and stroke), chronic non-specific lung disease (CNSLD, including lung disease, asthma, bronchitis, and emphysema), gastrointestinal disease (GI, including liver disease, gallbladder disease, and gastrointestinal disorders), arthritis (or rheumatism), cancer, and renal disease.

Diabetes, impaired glucose tolerance, osteoarthritis, rheumatoid arthritis, other arthritis, heart disease, hypertension, stroke, asthma, bronchitis or emphysema, osteoporosis, breast cancer, cervical cancer, other cancer, depression, anxiety or nervous disorder, and other psychiatric condition and chronic fatigue syndrome

All diseases taken at three level ICD 10 code

Metastatic cancer, congestive heart failure, dementia, renal failure, weight loss, hemiplegia, alcohol abuse, any tumour, cardiac arrhythmias, chronic pulmonary disease, coagulopathy, complicated diabetes, deficiency anaemias, fluid and electrolyte disorders, liver disease, peripheral vascular disorder, psychosis, pulmonary circulation disorders, HIV/AIDS, hypertension Diabetes mellitus, heart failure, stroke, ischemic heart disease, retinopathy, and nephropathy

Obesity, hypertension, and lipid disorder used as health risk 
Lindhagen et al. (2015)

Perez et al. (2020)

Pugh et al. (2016)

Quinones et al. (2011)

Quinones et al. (2019)

Rocca et al. (2016)

Ruel et al. (2014)

Ruel et al. (2014)

Ryan et al. (2018)

Siriwardhana et al. (2018)

Strauss et al. (2014)

Xu et al. (2018)

Zeng et al. (2014)

Zhu et al. (2018)
A list of 17 groups of diseases based on the Charlson Comorbidity Index As specified by Calderon-Larranaga et al. (2018)

Traumatic brain injury and a list of diseases with include "physical thyroid, obesity, hypertension, diabetes, chronic lung disease, cardiac conditions) and mental health (depression, anxiety, SUD, PTSD, bipolar disorder) conditions as well as other conditions such as hearing/tinnitus/vision disorders, headache, other pain, insomnia, memory loss, dementia, seizures, spinal cord injury/amputations/burns. Hypertension, heart disease, diabetes, cancer, lung disease, arthritis, and stroke

Heart disease (including myocardial infarction, coronary heart disease, angina, congestive heart failure, or other heart problems), hypertension, stroke (excluding transient ischemic attack), diabetes, arthritis, lung disease (including chronic bronchitis or emphysema and excluding asthma), and cancer (including any malignant tumours with the exception of skin cancer).

Depression, anxiety, substance abuse disorders, dementia, schizophrenia, hyperlipidemia, hypertension, diabetes, cardiac arrhythmia, coronary artery disease, stroke, congestive heart failure, arthritis, cancer (all types), asthma, chronic obstructive pulmonary disease, osteoporosis, chronic kidney disease.

Asthma, cardiovascular disease \& stroke (CVD), chronic obstructive pulmonary disease (COPD), diabetes, mood and anxiety disorders, any other mental disorders, hypercholesterolemia, and hypertension.

Anemia, hypertension, hypercholesterolemia, diabetes, arthritis, hepatitis, coronary heart disease, asthma, stroke, fracture, and cancer.

The list of 16 chronic conditions groups: cardiac conditions, cerebrovascular conditions, hypertension, diabetes, high cholesterol, chronic respiratory disease, liver disease, eye disease, cognitive impairment, arthritis, osteoporosis, cancer, Parkinson's disease, emotional/psychological condition, stomach ulcers, and varicose veins.

Diabetes, ischemic heart

disease, and chronic kidney disease

A list of 42 chronic and progressive morbidities as validated by a clinical consensus exercise with eight GPs: benign neoplasm of prostate, carcinoma in situ,

neurofibromatosis, hypothyroidism, diabetes mellitus, pure hypercholesterolaemia, obesity, hereditary haemolytic anaemia, senile/presenile dementia, hereditary and idiopathic peripheral neuropathy, primary angle glaucoma, cataract, corneal opacity and disorders of cornea, deafness, mitral stenosis, rheumatic heart disease, high blood pressure, hypertensive heart disease, hypertensive renal disease, angina pectoris, ischaemic heart disease, atrial fibrillation, congestive heart failure, cerebral atherosclerosis, cerebrovascular disease, intermittent claudication, chronic bronchitis, emphysema, extrinsic allergic alveolitis, pulmonary oedema, diffuse pulmonary fibrosis, nephritis and nephropathy, hydronephrosis, prostatism, rheumatoid arthritis, arthropathy, cervical spondylosis, Paget's disease of bone, osteoporosis, Nervous system injury, war injuries

Diabetes mellitus, heart disease (heart attack, angina), and stroke

The list of 17 chronic conditions of the Charlson Comorbidity Index

Diabetes type 2, hypertension, chronic kidney disease, coronary heart disease, stroke, and heart failure 